\title{
Tendências na alocação do tempo no Brasil: trabalho e lazer ${ }^{\star}$
}

\author{
Ana Luiza Neves de Holanda Barbosa ${ }^{\star \star}$
}

O objetivo deste artigo é documentar as tendências na alocação do tempo no Brasil entre 2001 e 2015. Em particular, pretende-se analisar a evolução das jornadas semanais de trabalho no mercado e em afazeres domésticos, além do tempo semanal dedicado ao lazer. A análise é feita por gênero e tem como base a Pesquisa Nacional por Amostra de Domicílios (PNAD), do Instituto Brasileiro de Geografia e Estatística (IBGE). Os resultados revelam que os homens desfrutam de mais horas de lazer do que as mulheres, ainda que haja uma tendência de redução dessa diferença ao longo do tempo. Há uma elevação do tempo dedicado ao lazer para ambos os sexos, mas este aumento se dá de forma mais acentuada para as mulheres. Os resultados mostram ainda que a ampliação do número de horas de lazer ao longo do período foi ocasionada por razões diversas entre homens e mulheres. Para eles, a elevação do lazer (de quatro horas semanais) pode ser explicada pela redução expressiva nas horas trabalhadas no mercado, enquanto para elas, o ganho de sete horas semanais de lazer deve-se à redução nas horas dedicadas aos afazeres domésticos.

Palavras-chave: Uso do tempo. Lazer. Oferta de trabalho. Gênero.

\footnotetext{
* Este artigo tem como base o texto "Tendências nas horas dedicadas ao trabalho e lazer: uma análise da alocação do tempo no Brasil”. Rio de Janeiro: Ipea, 2018 (Texto para Discussão, n. 2416). Uma versão bastante resumida do conteúdo deste artigo encontra-se na Nota Técnica "Tendências nas horas dedicadas ao trabalho e lazer: uma análise da alocação do tempo no Brasil” do Boletim de Mercado de Trabalho - Conjuntura e Análise. Rio de Janeiro: Ipea, n. 64, p 35-51, abril 2018. A autora agradece as sugestões e comentários de Carlos Eugênio Ellery Lustosa da Costa, Carlos Henrique Leite Corseuil, Maurício Cortez Reis, Simone Wajnman, de um parecerista anônimo e de participantes de um seminário no Ipea, isentando-os de quaisquer erros remanescentes. A autora também agradece a Maíra Albuquerque Penna Franca pela excelente assistência no processamento e na análise da Pesquisa Nacional por Amostra de Domicílios (PNAD).

** Instituto de Pesquisa Econômica Aplicada (Ipea), Rio de Janeiro-RJ, Brasil (ana.barbosa@ipea.gov.br; https://orcid. org/000-0002-2484-2291).
} 


\section{Introdução}

Ao longo dos últimos anos, algumas mudanças importantes foram observadas com relação ao uso do tempo dedicado ao trabalho remunerado (no mercado) e ao trabalho não remunerado (em afazeres domésticos). No Brasil, por exemplo, entre as mulheres, nota-se um leve aumento nas horas trabalhadas no mercado, enquanto para os homens ocorreu uma expressiva redução, segundo a Pesquisa Nacional por Amostra de Domicílios (PNAD). Com relação às horas despendidas em afazeres domésticos, verificam-se uma queda acentuada para as mulheres e um leve aumento para os homens. Portanto, as diferenças por gênero em relação ao uso do tempo referente ao trabalho têm se estreitado ao longo dos últimos anos. ${ }^{1}$

A literatura aponta alguns fatores que contribuíram para a redução da jornada de trabalho doméstico, em especial a das mulheres, gerando efeitos positivos na sua entrada na força de trabalho. Entre os principais fatores, encontram-se as transformações ocorridas na estrutura e composição das famílias, além de uma maior facilidade de arranjos formais e informais para o cuidado dos filhos e da maior eficiência na produção de bens e serviços domésticos (BROWNING; CHIAPPORI; WEISS, 2014; GREENWOOD; VANDENBROUCKE, 2008; GREENWOOD; SESHADRI; YORUKOGLU, 2005; GOLDIN, 1989; HECKMAN, 1974).

A evidência empírica sobre o uso do tempo dedicado a atividades não associadas ao trabalho no mercado e em afazeres domésticos também já é bem estabelecida na literatura. 0 uso do tempo dedicado ao lazer, por exemplo, tem recebido especial atenção em anos recentes (KURODA, 2010, 2013; AGUIAR; HURST; KARABARBOUNIS, 2012; AGUIAR; HURST, 2007). Essas evidências só se tornam possíveis em função da existência de pesquisas específicas de uso do tempo que coletam informações sobre como os indivíduos alocam o seu tempo, não só no trabalho (remunerado e não remunerado), mas também em educação e no lazer, entre outras diversas atividades da rotina diária das pessoas (BIRCH; LE; MILLER, 2009; AGUIAR; HURST; KARABARBOUNIS, 2012). A ausência destes tipos de pesquisa no Brasil dificulta as análises sobre o uso do tempo direcionado a atividades não vinculadas ao trabalho, seja ele remunerado ou não.

O objetivo deste artigo é documentar as tendências na alocação do tempo no Brasil entre 2001 e 2015. Em particular, pretende-se analisar a evolução das jornadas semanais de trabalho no mercado e em afazeres domésticos, além do tempo semanal dedicado ao lazer. Dada a indisponibilidade de pesquisas específicas sobre uso do tempo no Brasil, a definição de lazer adotada neste estudo é feita de forma residual, isto é, lazer é definido como o tempo não dedicado às atividades de trabalho (remunerado e não remunerado). A análise é feita por gênero e tem como base a Pesquisa Nacional por Amostra de Domicílios (PNAD) do Instituto Brasileiro de Geografia e Estatística (IBGE). A metodologia adotada se baseia no estudo de Aguiar e Hurst (2007), que documentam as tendências na alocação

\footnotetext{
${ }^{1}$ A redução da desigualdade de horas despendidas no trabalho doméstico ocorre na maior parte dos países ocidentais. Vale observar que, se a análise se restringir à população ocupada, a redução nessas disparidades é ainda maior (UNITED NATIONS, 2015).
} 
do tempo ao longo de um período de 40 anos para os Estados Unidos. Duas abordagens são utilizadas. A primeira é uma análise descritiva da evolução da média amostral de cada atividade de uso do tempo (horas de trabalho no mercado, em afazeres domésticos e dedicadas ao lazer) no período 2001-2015. A segunda trata de condicionar as variações das atividades do uso do tempo em variáveis demográficas.

Os resultados revelam que os homens desfrutam de mais horas de lazer do que as mulheres, ainda que haja uma tendência de redução dessa diferença ao longo do tempo. Há uma elevação do tempo dedicado ao lazer para ambos os sexos, mas esse aumento se dá de forma mais acentuada para as mulheres. Os resultados mostram ainda que a ampliação no número de horas de lazer ao longo do período foi ocasionada por razões diversas entre homens e mulheres. Para eles, a elevação do lazer (de quatro horas semanais ao longo de 2001 a 2015) pode ser explicada por uma redução expressiva nas horas trabalhadas no mercado em comparação com o leve aumento ocorrido nas horas dedicadas aos afazeres domésticos, enquanto para elas, o ganho de sete horas semanais de lazer no período 2001-2015 pode ser explicado por uma redução nas horas dedicadas aos afazeres domésticos em relação à elevação pouco acentuada nas horas direcionadas ao trabalho no mercado.

A seguir apresenta-se o arcabouço teórico utilizado nos estudos sobre alocação de uso do tempo e são abordadas as diversas definições de lazer utilizadas na literatura. Posteriormente é mostrada a base de dados utilizada neste trabalho, bem como a evolução do tempo despendido no trabalho no mercado e em afazeres domésticos e daquele dedicado ao lazer no Brasil ao longo do período 2001-2015. Discute-se, ainda, a metodologia utilizada para análise das tendências no uso do tempo e são apresentados os principais resultados deste estudo. Por fim, são tecidas as considerações finais. 0 Anexo traz alguns gráficos e tabelas adicionais, que servem como fonte para algumas análises deste texto.

\section{Arcabouço teórico na alocação do uso do tempo}

O tempo é um recurso cada vez mais escasso nos dias atuais. Uma análise detalhada do comportamento de uma economia de mercado e de suas implicações passa pelo entendimento do comportamento do tempo fora do mercado (AGUIAR; HURST, 2007). 0 uso do tempo pode se dar das mais diversas formas: dedicado ao cuidado dos filhos ou dependentes, aos afazeres domésticos, às atividades fisiológicas e de higiene pessoal, ao cuidado com a saúde e ao lazer. Nesse contexto, a dicotomia padrão entre trabalho de mercado e o termo "lazer" não distingue se a hora não dedicada ao trabalho de mercado é despendida em cozinhar ou assistir à televisão, por exemplo. Não distingue também o fato de que o produto consumido ou qualquer atividade realizada fora do mercado pode ser (e, em geral, é) fruto de uma combinação do uso de dois insumos: de bens de mercado e do uso do tempo. ${ }^{2}$

\footnotetext{
${ }^{2}$ Ao cozinhar, por exemplo, uma pessoa certamente faz uso tanto de alimentos e ingredientes (entre outros bens de mercado) quanto de um determinado tempo dedicado à atividade em questão.
} 
Becker (1965) foi o primeiro a formalizar a produção doméstica em um modelo neoclássico de decisão do consumidor. Seu artigo seminal apresenta os fundamentos analíticos para o estudo da produção doméstica e da alocação do tempo no contexto da família, ao permitir uma classe muito mais rica e mais ampla de modelos, preferências e atitudes do consumidor do que o arcabouço teórico tradicional até então disponível (BECKER, 1965, 1976; GRONAU, 1986; HECKMAN, 2014; BROWNING; CHIAPPORI; WEISS, 2014).

O ponto central desta teoria é que um indivíduo (ou família) é tanto consumidor quanto produtor de produtos e/ou atividades. O consumidor, portanto, consome não só produtos, mas também atividades, ambos produzidos pelo próprio com base em dois tipos de insumos: bens de mercado e tempo. Nesse contexto, entender como o tempo é alocado fora do mercado de trabalho é especialmente importante na medida em que a elasticidade de substituição entre o insumo bem de mercado e o insumo tempo pode divergir de forma significativa entre funções de produção dos diferentes produtos ou atividades que geram utilidade ao consumidor. A definição da atividade “lazer” depende, portanto, do grau de substituição entre esses dois insumos. De outra forma, o lazer é muito mais uma função da tecnologia do que das preferências.

0 restante desta seção apresenta um exemplo bastante simples do modelo de Becker e mostra que o trabalho no mercado é apenas um dos muitos usos do tempo que podem produzir bens de consumo. ${ }^{3}$ No exemplo, a utilidade do indivíduo é definida sobre um vetor de dois bens (commodities): $Z_{1}$ e $Z_{2} \cdot{ }^{4}$ Essas commodities são produzidas com base no uso de dois bens de mercado, $x_{1}$ e $x_{2}$, assim como no uso de determinadas unidades de tempo, $h_{1}$ e $h_{2}$, de acordo com as funções de produção (Constant Elasticity of Substitution - CES) com parâmetros de elasticidade substituição $\sigma$ e $\eta$, respectivamente.

$Z_{1}=\left(x_{1}^{\frac{\sigma-1}{\sigma}}+h_{1}^{\frac{\sigma-1}{\sigma}}\right)^{\frac{\sigma}{\sigma-1}}$

$Z_{2}=\left(x_{2}^{\frac{\eta-1}{\eta}}+h_{2}^{\frac{\eta-1}{\eta}}\right)^{\frac{\eta}{\eta-1}}$

Assume-se que $\sigma>1$ e $\eta\left\langle 1\right.$. Com isso, o bem de mercado $x_{1}$, substituto relativamente próximo à unidade de tempo $h_{1}$, faz com que a atividade $Z_{1}$ seja similar à produção doméstica e o bem de mercado $x_{2}$, substituto próximo à unidade de tempo $h_{2}$, faz com que a atividade $Z_{2}$ seja similar à atividade de lazer.

$O$ agente vive em um período com a dotação de tempo igual a um, que é alocado em trabalho no mercado $L, h_{1}$ e $h_{2}$. 0 agente se defronta com um salário de mercado $w$ e preços $p_{1}$ e $p_{2}$.

0 consumidor se defronta com dois problemas neoclássicos usuais: o problema da firma na produção das commodities $Z_{1}$ e $Z_{2}$ e o problema do consumidor de maximizar a

\footnotetext{
3 Este exemplo é apresentado em Aguiar e Hurst (2007), com algumas pequenas modificações na notação.

${ }^{4}$ Vale observar uma restrição desse modelo: a hipótese implícita é a de modelo unitário, ou seja, não se considera a possibilidade de alocação intrafamiliar de recursos.
} 
utilidade derivada do consumo de $Z_{1}$ e $Z_{2}$. 0 problema da firma na produção de $Z_{1}$ e na produção de $Z_{2}$ pode ser descrito, respectivamente, da seguinte forma:

Min $p_{1} x_{1}+w h_{1}$ sujeito a: $Z_{1}=\left(x_{1}^{\frac{\sigma-1}{\sigma}}+h_{1}^{\frac{\sigma-1}{\sigma}}\right)^{\frac{\sigma}{\sigma-1}}$

Min $p_{2} x_{2}+$ wh sujeito a: $Z_{2}=\left(x_{2}^{\frac{\eta-1}{\eta}}+h_{2}^{\frac{\eta-1}{\eta}}\right)^{\frac{\eta}{\eta-1}}$

A minimização de custo implica que o preço de cada unidade de $Z_{1}$ e $Z_{2}$ é, respectivamente, dado por:

$q_{1}=\left(p_{1}^{1-\sigma}+w^{1-\sigma}\right)^{\frac{1}{1-\sigma}}$
$q_{2}=\left(p_{2}^{1-\eta}+w^{1-\eta}\right)^{\frac{1}{1-\eta}}$

Assim, o problema do consumidor pode ser escrito da seguinte forma:

$\operatorname{Max} U\left(Z_{1}, Z_{2}\right)=\delta \ln Z_{1}+(1-\delta) \ln Z_{2}$ sujeito a: $q_{1} Z_{1}+q_{1} Z_{1}=w$

A restrição de tempo dada por $h_{1}+h_{2}+L=1$ é inerente à restrição orçamentária e as restrições de não negatividade de cada uso do tempo são não ativas (non bindings) em função das condições Inada da utilidade e produção (INADA, 1963). As condições de primeira ordem implicam que:

$\frac{Z_{1}}{Z_{2}}=\frac{\delta}{(1-\delta)} \frac{q_{2}}{q_{1}}$

Com base na restrição orçamentária, tem-se que:

$Z_{1}=\delta \frac{w}{q_{1}} \quad$ e $\quad Z_{2}=(1-\delta) \frac{w}{q_{2}}$

Com a aplicação do lema de Sheppard na função custo da produção doméstica de $Z_{1}$ e de $Z_{2}$, dado que essa tecnologia apresenta retornos constantes de escala, tem-se que:

$h_{1}=\frac{\partial q_{1}}{\partial w} Z_{1}=\delta\left(\frac{w}{q_{1}}\right)^{1-\sigma}=\delta \frac{w^{1-\sigma}}{p_{1}^{1-\sigma}+w^{1-\sigma}}$

e

$h_{2}=\frac{\partial q_{2}}{\partial w} Z_{2}=(1-\delta)\left(\frac{w}{q_{2}}\right)^{1-\eta}=(1-\delta) \frac{w^{1-\eta}}{p_{2}^{1-\eta}+w^{1-\eta}}$

Como $\sigma>1$, o tempo gasto na commodity $Z_{1}\left(h_{1}\right)$ é decrescente no salário e crescente no preço do bem de mercado $\left(p_{1}\right)$. De forma semelhante, o tempo gasto na segunda commodity $Z_{2}\left(h_{2}\right)$ é crescente no salário e decrescente no preço do bem de mercado $\left(p_{2}\right)$, dado que $\eta<1$. A oferta de trabalho no mercado pode ser calculada como:

$L=1-h_{1}-h_{2}$

Para avaliar como os parâmetros tecnológicos influenciam a elasticidade de oferta de trabalho, considera-se o caso em que $\sigma>1$ e $\eta=1$. Pelas equações anteriores, pode-se notar que a última hipótese implica que $h_{2}$ é constante (igual a 1- $\delta$ ). Portanto, qualquer redução em $h_{1}$ devido a um aumento em $w$ ou a uma redução em $p_{1}$ gera um aumento na oferta de 
trabalho $L$. De forma específica, a elasticidade não compensada da oferta de trabalho pode ser descrita da seguinte forma:

$\xi_{L}=\frac{d \ln L}{d \ln w}=(\sigma-1) \frac{h_{1}}{h_{2}+L}=(\sigma-1) \frac{w^{1-\sigma}}{p_{1}^{1-\sigma}+w^{1-\sigma}}$

Neste caso, a $\xi_{L}$ é positiva e decrescente no salário $(w)$. A alta elasticidade de substituição entre o bem de mercado $x_{1}$ e o tempo dedicado à produção doméstica $\left(h_{1}\right)$ é o que faz com que a elasticidade de oferta de trabalho não compensada $\left(\xi_{L}\right)$ seja positiva. De forma alternativa, se $\sigma=1$ e $\eta<1$, tem-se que:

$\xi_{L}=\frac{d \ln L}{d \ln w}=(\eta-1) \frac{w^{1-\eta}}{p_{1}^{1-\eta}+w^{1-\eta}}$

Neste caso, a $\xi_{L}$ é negativa e crescente no salário (w). Ou seja, à medida que o salário aumenta ou o preço dos bens usados na produção da commodity lazer se reduz, a oferta de trabalho de mercado diminui. ${ }^{5}$

Na situação mais geral, $\sigma>1$ e $\eta<1$, a sensibilidade da oferta de trabalho no mercado a variações de salários e preços depende da tecnologia e das preferências. ${ }^{6} 0$ caso simétrico $\delta=1-\delta, p_{1}=p_{2}, \sigma-1=1-\eta$ gera horas de trabalho no mercado constantes devido a uma redução em $h_{1}$, ou seja, no tempo dedicado à produção doméstica,e aumento em $h_{2}$, ou seja, no lazer.

0 exemplo apresentado nesta seção tenta mostrar que a forma como agentes alocam o seu tempo fora do trabalho no mercado influencia diretamente a oferta de trabalho no mercado. Em particular, faz diferença se as atividades não associadas ao mercado têm ou não substitutos próximos. Esta análise ajuda no entendimento dos fatores que geram mudanças das elasticidades de oferta de trabalho ao longo do tempo ou entre grupos demográficos e variações das jornadas e do nível de emprego. Além disso, a compreensão da alocação do tempo é importante para distinguir o consumo efetivo à la Becker (1965), resultante de uma função de produção doméstica que usa despesas com bens de mercado e o tempo como insumos, do consumo ou despesa (gasto) direta com bens de mercado (AGUIAR; HURST, 2005a, 2005b). De forma geral, as tendências descritas nas próximas seções são úteis para direcionar a escolha dos parâmetros para as funções utilidade e produção doméstica em modelos que analisam o comportamento dos consumidores diante de choques no mercado de trabalho e na produção doméstica.

\section{Definição de lazer}

As pesquisas domiciliares designadas para medir atividade de trabalho utilizam, em geral, apenas a categoria de uso do tempo associada às horas de trabalho no mercado.

\footnotetext{
$\overline{5}$ Kopecky (2005) e Vandenbroucke (2005) exploram de forma mais detalhada essa característica ao explicarem a redução significativa da jornada de trabalho no mercado ao longo do século XX.

${ }^{6}$ Como Aguiar e Hurst (2007) chamam a atenção, os parâmetros de preferência estão implícitos na forma reduzida devido à natureza (formato) $\log \log$ da função utilidade. Com funções de utilidade mais gerais, parâmetros da função utilidade entrariam na expressão da elasticidade de oferta de trabalho de forma explícita.
} 
Como resultado, o lazer é quase universalmente definido como tempo gasto fora do trabalho no mercado. Há pouca precisão nessa definição, pois ela tem um conteúdo que pode incluir trabalho em afazeres domésticos, trabalho voluntário, entre outros. No entanto, mesmo se, da dotação total do tempo, forem descontadas todas as atividades de trabalho (mercado e não mercado), o tempo dedicado ao lazer, definido dessa forma residual, pode ainda conter atividades que tenham substitutos muito próximos de bens de mercado. ${ }^{7}$ Quando é possível distinguir categorias, a definição de atividades associadas ao lazer com base em pesquisas de uso do tempo é feita de forma mais objetiva. A Classificação Internacional de Atividades para Estatísticas de Uso do Tempo (International Classification of Activities for Time Use Statistics - Icatus), realizada pela Divisão Estatística das Nações Unidas, engloba todas as atividades que uma pessoa pode despender durante as 24 horas de um dia. 0 princípio básico da Icatus é o de que atividades diárias podem ser categorizadas em atividades produtivas e não produtivas de um ponto de vista econômico. A estrutura resultante dessa classificação destaca o tempo gasto com todas as formas de trabalho, assim como o tempo gasto em atividades pessoais, visando obter estatísticas do tempo gasto com estudo, socialização, exercício e em muitas outras atividades que definem o bem-estar geral da população.

Em geral, os estudos empíricos distinguem quatro categorias de tempo (ROBINSON; GODBEY, 1999): trabalho remunerado; afazeres domésticos e cuidado da família; tempo pessoal; e tempo livre (ou lazer). 0 primeiro tipo é associado ao tempo contratado e dedicado ao trabalho vinculado ao mercado e, neste caso, são consideradas todas as atividades realizadas no local de trabalho. 0 segundo (tempo comprometido) cobre todas as atividades em afazeres domésticos, cuidado de filhos e dependentes, compras para casa, entre outras. A literatura recente sobre o tema tem reconhecido que este segundo tipo precisa ser adicionado ao trabalho remunerado (ROBINSON; GODBEY, 1999). Assim, a maior parte das atividades economicamente produtivas pode capturar os dois tipos de trabalho em uma sociedade: o remunerado e o não remunerado. A terceira categoria de tempo refere-se às necessidades biológicas do ser humano e inclui atividades como dormir, comer e as de higiene pessoal. Trata-se de um tempo dedicado a atividades funcionais e de cuidados pessoais que todos os indivíduos precisam para viverem de forma efetiva em uma sociedade. Há, obviamente, um grau de flexibilidade ou elasticidade dessas atividades, na medida em que muitas delas têm uma qualidade discricionária motivada tanto pela busca do prazer quanto pelo estilo de vida. A quarta e última categoria - tempo livre - envolve as atividades restantes e as que presumidamente envolvem a escolha total do indivíduo. Tais atividades englobam não só as culturais, de sociabilidade e hobbies, por exemplo, mas também atividades de "semilazer", como a educação de adultos, e atividades ligadas à religião, entre outras instituições/organizações.

\footnotetext{
7 Por exemplo, o tempo gasto na educação é um investimento no capital humano, que gera o consumo adicional de bens no futuro.
} 
O já citado estudo de Aguiar e Hurst (2007) faz uso de quatro medidas de lazer: atividades que geram utilidade direta ao consumidor (tempo dedicado a entretenimento/ atividades sociais e de recreação ativa); atividades que geram utilidade direta ao consumidor e podem servir de insumos intermediários, como aquelas fisiológicas/biológicas e de cuidados pessoais; atividades que geram utilidade direta ao consumidor e servem como insumos intermediários e tempo gasto diretamente no cuidado primário e educacional dos filhos; e tempo não dedicado a atividades do trabalho em mercado e ao trabalho em afazeres domésticos.

Para Aguiar e Hurst (2007), portanto, as diferentes definições de lazer estão atreladas à capacidade de substituição entre o tempo e os insumos utilizados na produção dos bens (commodities) finais. A primeira definição é a mais restrita e se aproxima mais do arcabouço em que o insumo principal do lazer é o tempo e que essas atividades têm um baixo grau de substituição com bens de mercado, embora possam envolver bens de mercado complementares. A falta de substitutos de mercado decorre do fato de que as próprias atividades podem gerar diretamente utilidade para o consumidor, tais como assistir à televisão, descansar, ir a festas, entre outras formas de entretenimento. A segunda definição inclui a primeira medida de lazer, bem como o tempo gasto em dormir, comer e cuidados pessoais. ${ }^{8}$ A terceira definição de lazer abarca a segunda definição mais o tempo gasto em cuidado infantil primário e educacional. A quarta e última definição, a de que o lazer é o uso do tempo residual do trabalho total, certamente, é a mais abrangente entre as quatro adotadas pelo estudo, no sentido de haver alta capacidade de substituição das atividades desse tipo de tempo com bens de mercado.

Aguiar e Hurst (2007) mostram, no entanto, que, apesar da distinção pouco significativa na magnitude entre essas quatro medidas, as tendências de aumento de lazer na economia americana ao longo do tempo são bastante semelhantes entre elas.

\section{Base de dados}

O Brasil não possui ainda uma pesquisa específica em âmbito nacional sobre o uso do tempo, embora algumas experiências tenham sido realizadas sobre o tema. ${ }^{9}$ Os primeiros dados nacionais e oficiais sobre atividades do uso do tempo no Brasil começaram a ser obtidos em 1992, quando o IBGE incluiu na PNAD dois quesitos relacionados ao uso do tempo: um que indagava sobre a realização de afazeres domésticos por parte de todos os membros do domicílio e outro questionando sobre o tempo médio gasto semanalmente

\footnotetext{
$\overline{8}$ Biddle e Hamermesh (1990) ressaltam que determinadas atividades de tempo podem aumentar a produção dentro e fora do mercado. Os autores constroem um modelo no qual o tempo gasto em dormir, por exemplo, é uma variável de escolha que aumenta a produtividade e entra diretamente na função utilidade. Além disso, eles dão forte evidência empírica mostrando que dormir é, de fato, uma variável de escolha na qual os indivíduos otimizam. Por exemplo, indivíduos dormem mais nos fins de semana e em férias. Questões semelhantes se aplicam amplamente para tempo gasto em comer e em cuidados pessoais. ${ }^{9}$ Ver Barbosa (2018) para uma análise sobre a experiência brasileira em relação ao desenvolvimento de pesquisas de uso do tempo.
} 
pelas pessoas ocupadas no deslocamento entre o domicílio e o local de trabalho. A incorporação destas duas perguntas no questionário da pesquisa possibilitou discussões sobre a divisão sexual do trabalho, responsabilidade feminina pelas tarefas domésticas e dupla jornada de trabalho para as mulheres brasileiras (FONTOURA et al., 2010).

A análise empírica apresentada neste texto utiliza informações da PNAD, realizada entre 1967 e 2015 pelo IBGE. A PNAD é uma pesquisa domiciliar anual, com representatividade nacional, contendo dados sobre características gerais da população, migração, educação, trabalho. Esta pesquisa não é específica de uso do tempo e, por isso, a única medida possível de lazer é a definição mais abrangente adotada em Aguiar e Hurst (2007). Ou seja, lazer é definido de forma residual: a dotação total do tempo é descontada do trabalho no mercado e do trabalho em afazeres domésticos. Importante ressaltar que, neste artigo, o tempo dedicado ao trabalho no mercado refere-se à jornada de trabalho remunerado mais o tempo de deslocamento casa-trabalho-casa. Assim, as principais variáveis da PNAD utilizadas para a definição de lazer nesse estudo são as horas semanais trabalhadas no mercado, as dedicadas aos afazeres domésticos e as de deslocamento casa-trabalho-casa.

As horas normalmente trabalhadas no mercado por semana, disponibilizadas a partir de 1976, correspondem às horas habitualmente trabalhadas por semana no trabalho principal, no secundário e nos demais trabalhos remunerados que a pessoa tinha na semana de referência. A definição de trabalho no mercado (ou trabalho em atividade econômica) segue a definição de trabalho adotada pela PNAD do IBGE até 2015, compreendendo o trabalho remunerado, o não remunerado exercido durante pelo menos uma hora na semana em determinadas atividades e na produção para o próprio consumo ou na construção para o próprio uso. As atividades de trabalho não remunerado são as exercidas em: ajuda a membro da unidade domiciliar que tivesse trabalho como empregado na produção de bens primários (atividades da agricultura, silvicultura, pecuária, extração vegetal ou mineral, caça, pesca e piscicultura), conta própria ou empregador; ajuda à instituição religiosa, beneficente ou de cooperativismo; ou como aprendiz ou estagiário. Foram incluídas também as horas que a pessoa habitualmente ocupava fora do local de trabalho em tarefas relacionadas com a sua ocupação no trabalho considerado. ${ }^{10}$

A variável sobre o tempo que os indivíduos gastam nos deslocamentos de casa para o trabalho (código V9057), disponibilizada pelo IBGE desde 1992, é construída como variável categórica com os seguintes intervalos: até trinta minutos; entre trinta minutos e uma hora; entre uma e duas horas; e duas horas ou mais. Com base no método adotado em Pereira e Schwanen (2013) e sugerido em Bussab e Morettin (1987), o tempo médio de deslocamento das viagens foi calculado utilizando o ponto médio de cada categoria intermediária e o

\footnotetext{
$\overline{10}$ A definição atual de trabalho remunerado adotada pelo IBGE difere da utilizada neste artigo. Com a introdução da PNAD Contínua (PNAD C), implantada a partir de janeiro de 2012, a definição de trabalho remunerado passa a excluir o trabalho na produção para o próprio consumo ou a construção para o próprio uso. A PNAD Contínua, com amostra de cobertura nacional, substituiu as estatísticas sobre mercado de trabalho obtidas a partir da Pesquisa Mensal de Emprego (PME) e da PNAD.
} 
primeiro ponto da última categoria aberta. ${ }^{11}$ Neste trabalho, foram considerados o tempo de deslocamento de casa para o trabalho e o da volta do trabalho para casa. ${ }^{12}$

A definição de jornada de trabalho no mercado adotada neste artigo é dada pela soma das horas normalmente trabalhadas no mercado por semana mais o tempo semanal de deslocamento casa-trabalho-casa.

As horas dedicadas aos afazeres domésticos, disponibilizadas a partir de 2001, são contabilizadas semanalmente. ${ }^{13}$ A PNAD define afazeres domésticos como a realização de tarefas ou atividades que não se enquadram no conceito de trabalho remunerado, a saber: arrumar ou limpar toda ou parte da moradia; cozinhar ou preparar alimentos, passar roupa, lavar roupa ou louça, utilizando, ou não, aparelhos eletrodomésticos para executar estas tarefas para si ou para outro(s) morador(es); orientar ou dirigir trabalhadores domésticos na execução das tarefas domésticas; cuidar de filhos ou menores moradores; ou limpar o quintal ou terreno que circunda a residência. Vale observar que, para chegar ao número de horas - tanto as normalmente trabalhadas na semana quanto as dedicadas aos afazeres domésticos -, a investigação da PNAD foi feita em horas inteiras, considerando trinta minutos ou mais como uma hora e desprezando os períodos inferiores a trinta minutos.

A definição de lazer adotada neste estudo compreende a dotação do tempo semanal de uma pessoa (168 horas semanais) menos as horas normalmente trabalhadas no mercado por semana (incluindo o tempo semanal gasto no deslocamento de casa para o trabalho) e as horas semanais habitualmente dedicadas aos afazeres domésticos. A amostra utilizada é composta por homens e mulheres com idade de 24 a 64 anos para o período de 2001 a 2015. ${ }^{14}$ Para manter a comparabilidade das PNADs ao longo do tempo, foi preciso harmonizá-las retirando as informações dos indivíduos moradores em áreas rurais da região Norte, pois apenas a partir de 2004 essas localidades passaram a fazer parte da amostra das PNADs.

Para análise da evolução do uso do tempo em trabalho e lazer no Brasil, serão utilizadas duas abordagens. A primeira é uma análise descritiva da evolução da média amostral de cada atividade de uso do tempo (horas de trabalho no mercado, em afazeres domésticos e dedicadas ao lazer) ao longo do período 2001-2015. A segunda trata de condicionar as variações das atividades do uso do tempo em variáveis demográficas. As duas abordagens são apresentadas nas próximas seções.

\footnotetext{
${ }^{11}$ É importante observar que esta pergunta no questionário da PNAD é feita apenas para as pessoas que declararam fazer viagens de casa direto para o trabalho. Pessoas que trabalham em casa ou cujo emprego se localiza no mesmo terreno onde moram não são consideradas.

${ }^{12}$ o tempo referente ao deslocamento da volta do trabalho para casa foi imputado como o mesmo tempo do deslocamento de casa para o trabalho.

13 Importante observar que ao longo do texto usamos os termos "trabalho não remunerado" ou "trabalho doméstico" como referência ao trabalho dedicado aos afazeres domésticos. Ambos têm definições distintas na PNAD: o primeiro está associado ao trabalho em ajuda a membro da unidade domiciliar que tivesse trabalho como empregado na produção de bens primários, como conta própria ou empregador, enquanto o trabalho doméstico está associado à posição ocupacional de emprego doméstico.

${ }^{14}$ A PNAD não foi a campo em 2010 em função do Censo Demográfico realizado pelo IBGE.
} 


\section{Trabalho e lazer ao longo do período 2001-2015}

\section{Trabalho remunerado e trabalho não remunerado}

Os Gráficos 1 e 2 mostram a evolução da oferta de trabalho remunerado e não remunerado, tanto na margem extensiva quanto na intensiva, para mulheres e homens entre 2001 e 2015. No que diz respeito à taxa de participação no mercado de trabalho, há uma diferença bastante expressiva entre os sexos ao longo do período. Em média, a taxa de participação dos homens supera a das mulheres em mais de 24 pontos percentuais (p.p.). 0 Gráfico 1 revela que a taxa de participação feminina no Brasil teve um aumento de 4 p.p. ao longo do período estudado, passando de $61 \%$, em 2001, para $65 \%$, em 2015 . Em uma análise dedicada a investigar os determinantes da participação feminina no Brasil, Queiroz e Aragon (2015) identificam que a educação, a condição de ser chefe de família e o acesso a creches colaboram para aumentar a inserção feminina no mercado de trabalho. ${ }^{15}$ A taxa de participação dos homens de 24 a 64 anos, ainda que bem mais alta do que a das mulheres, sofreu uma leve redução ao longo de todo o período: passou de $90 \%$ para $88 \%$, entre 2001 e 2015, com uma queda, portanto, de 2 p.p. (Gráfico 2).

\section{GRÁFICO 1}

Taxas de participação e de realização de afazeres domésticos e horas semanais de trabalho remunerado e não remunerado das mulheres

Brasil - 2001-2015

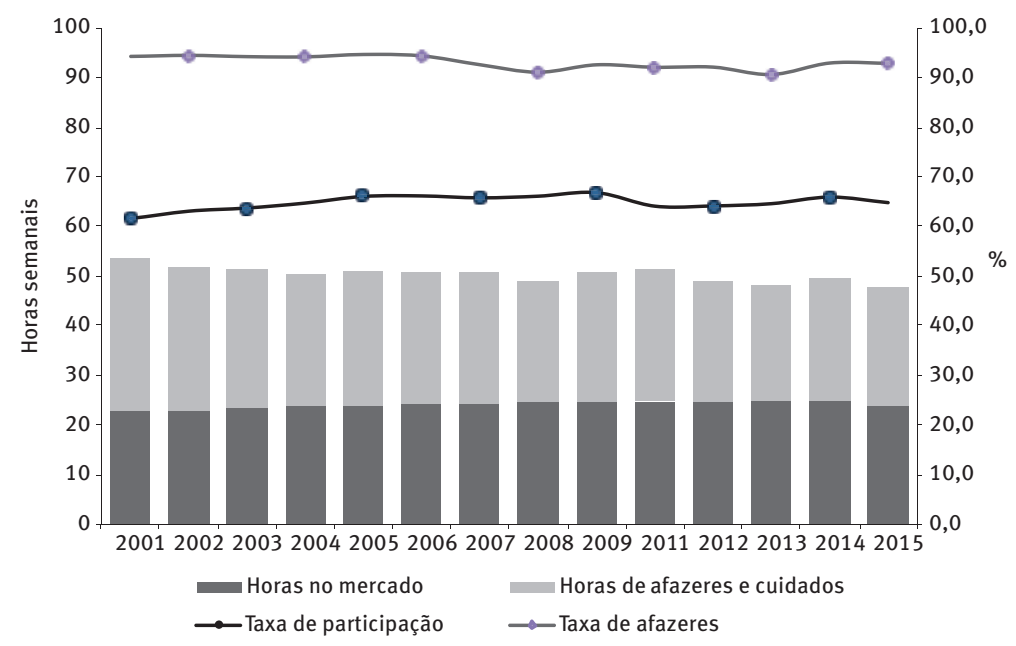

Fonte: IBGE. Pesquisa Nacional por Amostra de Domicílios - PNAD. Elaboração da autora.

\footnotetext{
$\overline{15} \mathrm{Na}$ comparação entre áreas metropolitanas e regiões não metropolitanas, os autores sugerem que as mulheres que moram nas últimas têm mais chance de ofertar trabalho, uma vez que nas grandes cidades há mais opções de lazer e amenidades (QUEIROZ; ARAGON, 2015).
} 
Com relação ao trabalho não remunerado na realização de afazeres domésticos, os dois gráficos revelam, novamente, uma diferença significativa entre homens e mulheres. Para o total de mulheres, mais de $91 \%$ realizavam afazeres domésticos (taxa de afazeres domésticos) ao longo de todo o período, enquanto para os homens essa proporção é bem menor, não ultrapassando 55\%. Quanto à evolução intertemporal da taxa de afazeres domésticos feminina, o Gráfico 1 mostra que ela se manteve relativamente estável durante período analisado. Já entre os homens, observou-se uma elevação de 10 p.p., passando de 45\% em 2001 para 55\% em 2015 (Gráfico 2). Vale destacar que, se apenas a população ocupada for considerada, a média da taxa de afazeres domésticos feminina, ao longo do período 2001-2015, se reduz para $75 \%$ (mulheres ocupadas), enquanto a média para os homens se mantém em torno de $50 \%$.

GRÁFICO 2

Taxas de participação e de realização de afazeres domésticos e horas semanais de trabalho remunerado e não remunerado dos homens

Brasil - 2001-2015

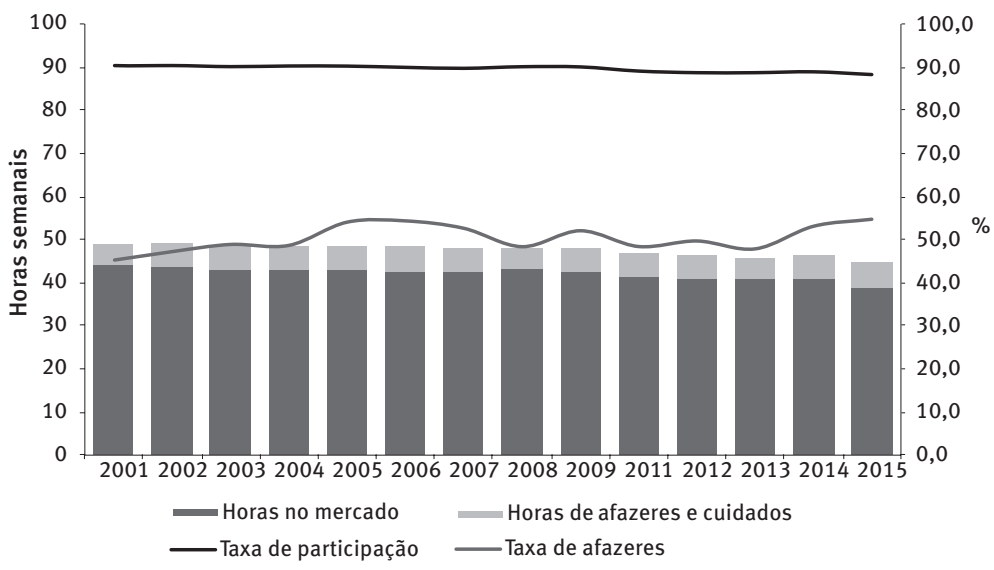

Fonte: IBGE. Pesquisa Nacional por Amostra de Domicílios - PNAD. Elaboração da autora.

Ao longo dos últimos anos, algumas mudanças importantes foram observadas com relação ao uso do tempo dedicado ao trabalho no mercado e ao trabalho em afazeres domésticos. ${ }^{16}$ Por um lado, o Gráfico 1 revela um aumento nas horas trabalhadas no mercado entre as mulheres até 2014 (de 23 para 25 horas semanais) e uma redução em 2015 (para 24 horas semanais). De forma semelhante aos resultados encontrados para a participação feminina no mercado de trabalho, Queiroz e Aragon (2015) sugerem que a educação e o acesso à creche têm impacto positivo na jornada de trabalho remunerado das mulheres brasileiras. No entanto, se a renda não vinculada ao trabalho for considerada, os efeitos na oferta de trabalho feminino (tanto participação quanto jornada) são negativos (QUEIROZ; ARAGÓN, 2015). Os homens, por sua vez, apresentaram uma redução de cinco horas semanais no

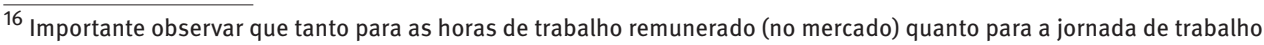
não remunerado (em afazeres domésticos) a média calculada, neste trabalho, é para a população total. Assim, atribuiu-se jornada de trabalho igual a zero para as pessoas desocupadas e inativas.
} 
período, passando de 44 para 39 horas, entre 2001 e 2015 (gráfico 2). ${ }^{17}$ Tais resultados se assemelham àqueles encontrados em Aguiar e Hurst (2007).

Com relação às horas despendidas em afazeres domésticos, o Gráfico 1 aponta uma redução significativa (de sete horas semanais) para as mulheres (de 31 horas, em 2001, para 24 horas semanais, em 2015), enquanto o Gráfico 2 mostra um aumento bastante pequeno para os homens (de cinco para seis horas semanais, no mesmo período). ${ }^{18}$ Também nesse caso os resultados são semelhantes aos encontrados em Aguiar e Hurst (2007). Essas diferenças por gênero quanto ao uso do tempo com relação ao trabalho não remunerado têm se estreitado ao longo dos últimos anos, não só no Brasil e nos Estados Unidos, mas na maior parte dos países do Ocidente (BROWNING; CHIAPPORI; WEISS, 2014).

Os Gráficos 1 e 2 ainda revelam outra informação importante quanto ao uso do tempo dedicado ao trabalho: se for considerado o total de horas trabalhadas (no mercado de trabalho e em afazeres domésticos), as mulheres trabalham mais do que os homens. Para ambos os sexos, verifica-se uma redução de trabalho total ao longo do período de análise: para as mulheres, o total de horas semanais trabalhadas diminuiu de 54 para 47 horas, entre 2001 e 2015. Para os homens, houve um decréscimo de quatro horas semanais, passando de 49 para 45 horas, no mesmo período. Portanto, em termos absolutos, as mulheres trabalhavam cinco horas a mais do que os homens em 2001 , sendo que essa diferença reduziu-se para duas horas, em 2015.

Como exposto anteriormente e de forma semelhante aos resultados encontrados em Aguiar e Hurst (2007), a redução do número de horas de trabalho total ao longo de todo o período de análise ocorre por razões diferentes entre homens e mulheres. Para elas, tal retração é explicada majoritariamente pela diminuição das horas de trabalho em afazeres domésticos, enquanto para os homens deve-se ao decréscimo preponderante das horas de trabalho no mercado.

Esta seção procurou mostrar a evolução da oferta de trabalho das mulheres e dos homens entre 2001 e 2015 . Algumas tendências e diferenças apresentadas reproduzem os fatos estilizados amplamente disseminados na literatura sobre o tema. Por exemplo, do ponto de vista da margem extensiva, a taxa de participação no mercado de trabalho dos homens supera de forma expressiva a das mulheres, ainda que essa diferença esteja se reduzindo ao longo do tempo. No entanto, com relação à taxa de afazeres domésticos, o oposto se verifica. Para o total de mulheres, a proporção das que os realizam é significativamente maior do que a dos homens. Do ponto de vista da margem intensiva, as diferenças entre 0 trabalho no mercado e o doméstico prevalecem. Homens dedicam mais horas de trabalho

\footnotetext{
$\overline{17}$ Se apenas a população ocupada for considerada, esses números aumentam de forma significativa. Para as mulheres, houve uma estabilidade nas horas trabalhadas no mercado ( 41 horas) ao longo do período de 2001 a 2014, havendo uma redução em 2015 (para 40 horas semanais). Os homens, por sua vez, apresentaram uma redução de quatro horas semanais, passando de 51 para 47 horas, no mesmo período.

${ }^{18}$ Para as mulheres ocupadas, as horas semanais dedicadas ao trabalho doméstico diminuíram de 23 para 19 horas, entre 2001 e 2015. Para os homens ocupados, não há praticamente alteração nas horas dedicadas ao trabalho doméstico em relação à população total masculina. No período de 2001 a 2015, os homens ocupados dedicaram, em média, cinco horas semanais ao trabalho doméstico.
} 
no mercado e menos horas no trabalho doméstico do que as mulheres. Essas diferenças em relação ao uso do tempo também têm se estreitado com o decorrer dos anos.

Lazer

O Gráfico 3 mostra a evolução do tempo dedicado ao lazer no período 2001-2015 no Brasil. Verifica-se uma elevação deste tempo tanto para homens quanto para mulheres. Em 2001, o tempo dedicado ao lazer correspondia a 119 horas semanais, para os homens, e 114 horas, para as mulheres, aumentando em 2015, respectivamente, para 123 e 121 horas semanais. Nota-se, portanto, que homens têm mais tempo de lazer do que as mulheres, 0 que se explica pelo fato de o trabalho total (remunerado mais não remunerado) ser menor para os homens em relação às mulheres. Vale observar que Aguiar e Hurst (2007) também observaram uma elevação do lazer ao longo do tempo nos Estados Unidos. No entanto, o tempo de lazer dos homens americanos é menor do que o das mulheres americanas, uma vez que o tempo total de trabalho masculino é maior do que o feminino.

0 aumento do tempo voltado para o lazer no Brasil ocorre por razões diversas entre homens e mulheres. Como visto anteriormente, os homens se defrontaram com uma redução nas horas de trabalho no mercado e uma estabilidade das horas dedicadas aos afazeres domésticos. Portanto, o que explica a elevação do lazer dos homens é a diminuição do tempo dedicado ao trabalho remunerado. Por sua vez, as mulheres se depararam com uma estabilidade da jornada de trabalho no mercado e uma redução de magnitude significativa nas horas despendidas na realização de afazeres domésticos. Assim, o que explica a elevação do tempo dedicado ao lazer das mulheres é o decréscimo do tempo dedicado à jornada de trabalho doméstico.

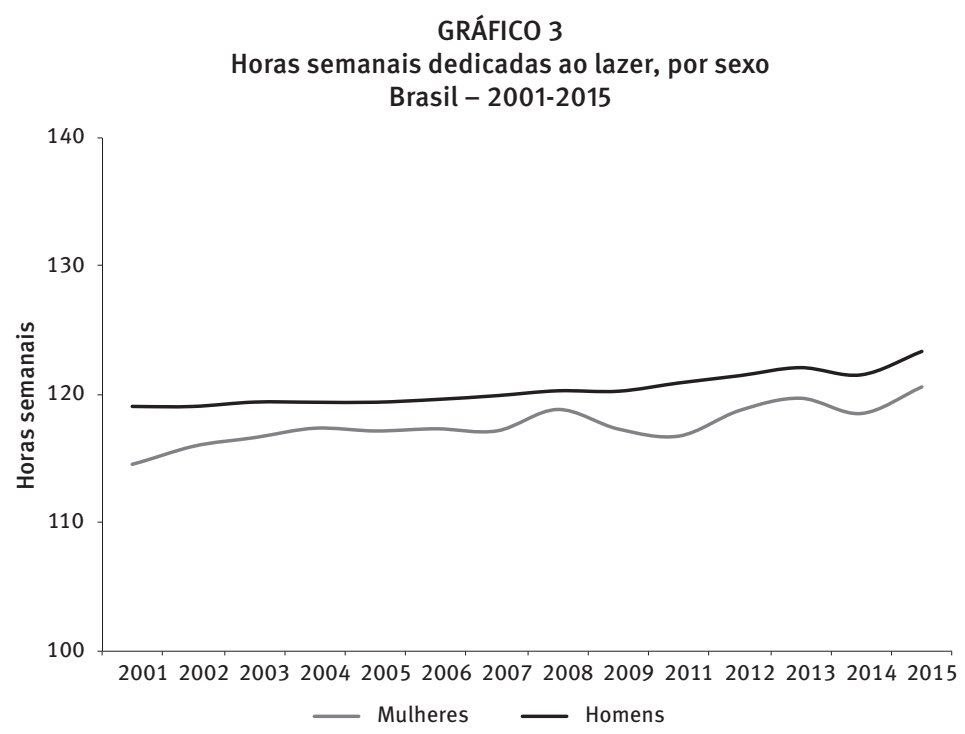

Fonte: IBGE. Pesquisa Nacional por Amostra de Domicílios - PNAD. Elaboração da autora. 


\section{Tendências na alocação do tempo no Brasil: análise de 2001 a 2015}

Esta seção tem como objetivo documentar as tendências na alocação do uso do tempo no período de 2001 a 2015 condicionadas a variáveis demográficas. Nas últimas décadas, o Brasil tem se defrontado com significativas transformações demográficas (CAMARANO, 2014). As mudanças ocorridas no início deste século ficam evidentes com os dados da Tabela 1, que mostram a composição demográfica das amostras usadas neste estudo para 2001, 2008 e 2015.

A Tabela 1 revela que os brasileiros ficaram mais velhos, mais educados, aumentaram a probabilidade de ficarem solteiros e têm tido menos filhos. Todas essas mudanças podem afetar a alocação do tempo de um indivíduo. Por exemplo, homens e mulheres com idade próxima aos 60 anos têm maior probabilidade de alocar menos tempo de trabalho no mercado do que indivíduos com cerca de 40 anos. Não seria surpresa, portanto, verificar que o tempo de lazer das pessoas mais velhas é maior do que o das mais novas. 0 crescimento do nível educacional da população também pode alterar a alocação do tempo dos homens e mulheres. Em Barbosa (2018), verifica-se que ter o ensino superior completo, por exemplo, implica uma jornada de trabalho no mercado maior do que ter o ensino superior incompleto, sendo essa diferença mais alta entre as mulheres. Com relação ao trabalho em afazeres domésticos, mulheres com maior nível educacional têm uma jornada menor do que aquelas com ensino superior incompleto. Para os homens, a jornada de trabalho doméstico é bem menor do que a das mulheres, não havendo diferença por escolaridade.

0 entorno familiar também pode influenciar sobremaneira a jornada de trabalho remunerado e não remunerado e, consequentemente, o tempo dedicado ao lazer. A Tabela 1 revela que o percentual de pessoas casadas tem se reduzido ao longo do tempo. De fato, o número de casamentos formais diminuiu enquanto o número de famílias monoparentais e o das pessoas morando sozinhas aumentaram nos últimos anos (CAMARANO; FERNANDES, 2014). 0 estado conjugal tem efeitos diferentes para homens e mulheres na jornada de trabalho no mercado e na de afazeres domésticos. Homens casados dedicam menos horas em afazeres domésticos do que homens solteiros, enquanto mulheres casadas dedicam mais horas do que as solteiras. Um ponto interessante é que essa relação é a oposta encontrada na análise da jornada de trabalho no mercado. Homens solteiros e mulheres solteiras têm mais tempo de lazer do que homens casados e mulheres casadas, respectivamente (BARBOSA, 2018). Ter menos filhos é outro exemplo de que alocação de tempo pode mudar. Nesse caso, devido ao menor tempo dedicado aos afazeres domésticos e cuidado de dependentes, o tempo de lazer, em especial o das mulheres, tem propensão a se elevar. Com relação aos homens, a jornada de trabalho em afazeres domésticos é a mesma independentemente da condição de ter filhos ou não. Como visto anteriormente, para os homens, o que afeta a evolução do tempo gasto com lazer, no período 2001-2015, é a jornada de trabalho no mercado (BARBOSA, 2018).

0 arcabouço utilizado para avaliar as tendências no uso do tempo nas atividades de trabalho no mercado, afazeres domésticos e lazer é condicionar cada uma dessas atividades 


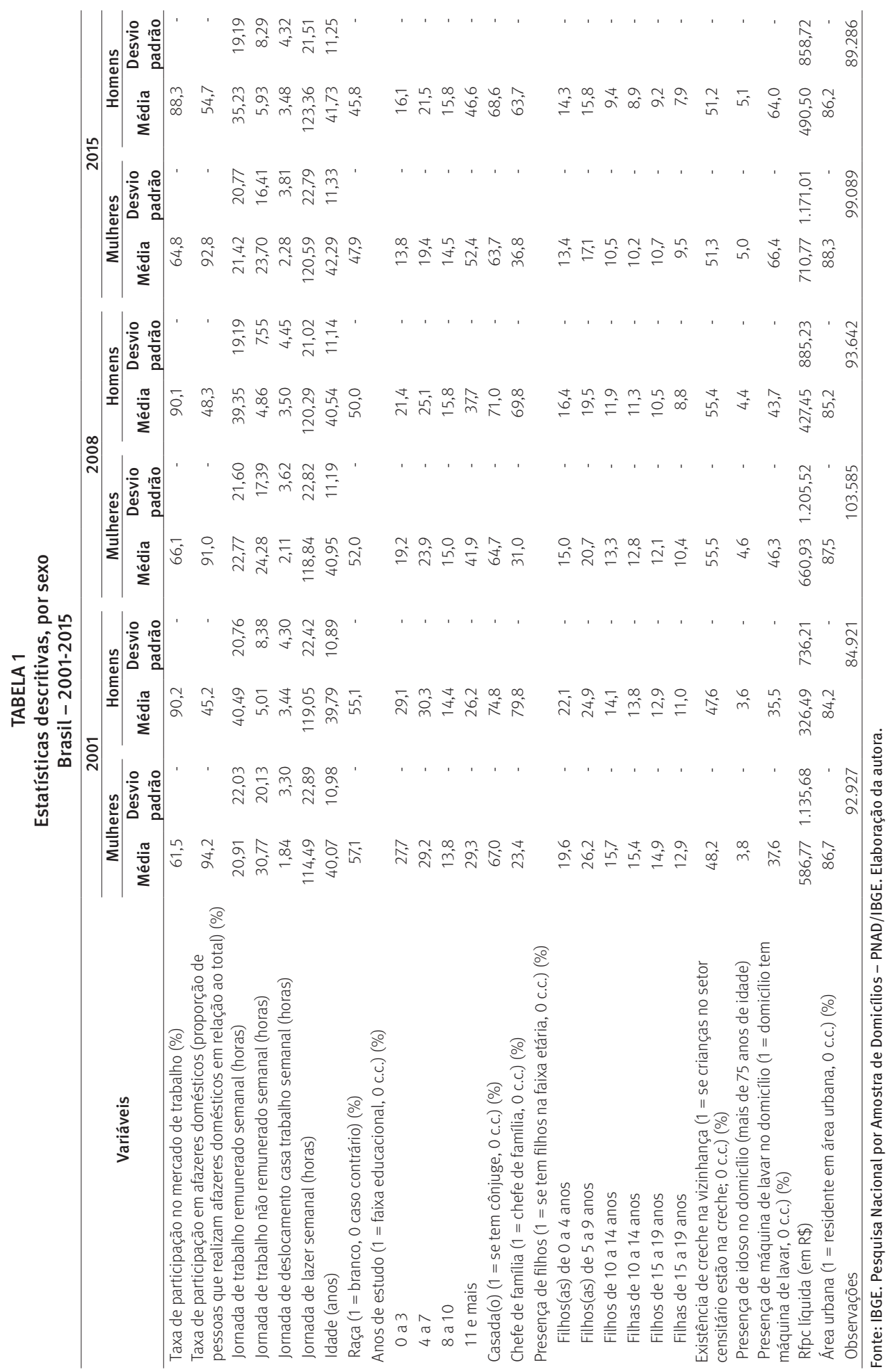


de uso do tempo nas diversas variáveis demográficas. A metodologia adotada neste estudo é uma extensão do modelo empregado por Aguiar e Hurst (2007). ${ }^{19}$ Além de variáveis usuais associadas a aspectos demográficos, foi incluída uma variável relacionada à oferta de creche no setor censitário no qual reside o homem ou a mulher. Para construção desta variável, seguiu-se a estratégia adotada em Costa (2007). Por meio do setor censitário da PNAD, a área onde há pelo menos uma criança de 0 a 5 anos estudando foi caracterizada como uma vizinhança em que existe oferta de creches e, assim, cria-se uma variável binária que indica se a mulher tem oferta de creche em sua área de residência. A vantagem dessa variável em relação às adotadas em outros estudos (QUEIROZ; ARAGÓN, 2015, por exemplo) é que a mesma tenta excluir a endogeneidade na simultaneidade da decisão da mãe de entrar para o mercado de trabalho e de colocar seu filho na creche. Dessa forma, a causalidade do "efeito-creche" torna-se mais consistente (BARBOSA; COSTA, 2017).

Ao ser uma alternativa para o cuidado dos filhos, a creche pode influenciar de forma significativa a decisão da entrada da mulher no mercado de trabalho e o seu uso do tempo de forma geral. A evidência empírica mostra que o acesso a arranjos formais (como creche e pré-escola) para o cuidado das crianças aumenta a participação das mulheres no emprego formal, bem como o número de horas trabalhadas das mães (PINHEIRO, 2018; QUEIROZ; ARAGÓN, 2015; POSADAS, 2012; BARROS et al., 2011; COSTA, 2007). Em uma análise descritiva, Barbosa e Costa (2017) mostram que, no período 2001-2015, mulheres com filhos entre 0 e 5 anos de idade matriculados em creche apresentaram uma jornada de trabalho no mercado em torno de duas horas e meia a mais do que aquelas com filhos que não estavam na creche. Quanto ao trabalho em afazeres domésticos, a relação oposta prevalece: as mulheres com filhos na creche trabalharam em torno de duas horas e meia a menos do que aquelas cujos filhos não estavam na creche. Essa diferença sugere que as creches representam uma redução do volume de obrigações domésticas das mulheres (PINHEIRO, 2018; BARBOSA; COSTA, 2017).

O modelo para análise das tendências do uso do tempo pode ser descrito pela equação (15), a ser estimada para homens e mulheres separadamente.

$$
\begin{aligned}
& T_{i t}^{j}=\alpha+\sum_{t=2002}^{n=13} \beta_{i j} D_{i j}+\gamma_{i d a d e} I d_{i t}+\gamma_{\text {raça }} R a c ̧ a_{i t}+\gamma_{\text {educa }} E_{d u c a_{i t}}+\gamma_{\text {casado }} \text { Casado }_{i t} \\
& +\gamma_{\text {chefe }} \text { Chefe }_{i t}+\gamma_{\text {filho }_{0 a 4}} \text { Filho }_{0 a 4_{i t}}+\gamma_{\text {fiho }_{5 a 9}} \text { Filho }_{5 a 9_{i t}}+\gamma_{\text {filho }_{0 a 14}} \text { Filho }_{10 a 14_{i t}} \\
& +\gamma_{\text {filha }_{10 a 14}} \text { Filha }_{10 a 14_{i t}}+\gamma_{\text {filho }_{15 a 19}} \text { Filho }_{15 a 19 i t}+\gamma_{\text {filha }_{15 a 19}} \text { Filha }_{15 a 19_{i t}}+\gamma_{\text {creche }} \text { Creche }_{\text {it }} \\
& +\gamma_{\text {idoso }} \text { Idoso }_{i t}+\gamma_{\text {renda }} \text { Renda }_{i t}+\gamma_{m \_l a v a r} m_{-} \text {lavar } i t+\varepsilon_{i, j}
\end{aligned}
$$

\footnotetext{
${ }^{19}$ Neste estudo, levam-se em conta diversas variáveis importantes que não foram contempladas em Aguiar e Hurst (2007). Uma exceção é que no estudo de Aguiar e Hurst (2007) foi incluída a variável referente ao dia da semana em que ocorreu a atividade do uso do tempo em questão. Como a PNAD não disponibiliza essa informação, ela não foi inserida no nosso modelo. Outra importante diferença deste estudo em relação ao de Aguiar e Hurst (2007) é que a estimação foi realizada com base em dados empilhados em função das características da PNAD.
} 
Nesta equação, $T_{i t}^{j}$ é o uso do tempo despendido na atividade $j$ para o indivíduo $i$ no ano $t$; $D_{i j}$ é uma variável dummy para cada ano; $I d_{i t}$ é um vetor de dummies de faixa de idade (24-29 anos; 30-39 anos; 40-49 anos, 50-59 anos e 60-64 anos de idade) que o indivíduo $i$ se inclui no ano $t$; $R a c ̧ a_{i t}$ é uma dummy igual a um quando o indivíduo $i$ for branco e zero quando não branco; $E d u c a_{i t}$ é um vetor de dummies de nível educacional (0-3 anos, 4-7 anos, 8-10 anos e 11 anos e mais de escolaridade) que o indivíduo $i$ se inclui no ano $t$; Casado $_{i t}$ é uma dummy igual a um se o indivíduo $i$ for casado no ano $t$; Chefe $e_{i t}$ é uma dummy igual a um se o indivíduo $i$ for chefe do domicílio no ano $t$; Filho_0a4 ${ }_{i t}$ é uma dummy igual a um se o indivíduo $i$ tiver pelo menos um(a) filho(a) entre 0 e 4 anos de idade no ano $t$; Filho_ $5 a 9_{i t}$ é uma dummy igual a um se o indivíduo $i$ tiver pelo menos um(a) filho(a) entre 5 e 9 anos de idade no ano $t$; Filho_10a14 it é uma dummy igual a um se o indivíduo $i$ tiver pelo menos um filho entre 10 e 14 anos de idade no ano $t$; Filha_10a14 it é uma dummy igual a um se o indivíduo $i$ tiver pelo menos uma filha entre 10 e 14 anos de idade no ano $t$; Filho_15a19 ${ }_{i t}$ é uma dummy igual a um se o indivíduo $i$ tiver pelo menos um filho entre 15 e 19 anos de idade no ano $t$; e Filha_15a19 é uma dummy igual a um se o indivíduo $i$ tiver pelo menos uma filha entre 15 e 19 anos de idade no ano $t$. A escolha de variáveis associadas a diversas faixas etárias e ao sexo dos filhos foi feita com a finalidade de captar algum efeito de que filhos mais novos demandam mais cuidados dos pais (e, portanto, maior alocação do tempo para cuidados dos filhos) e filhas mais velhas, por questões culturais em relação à divisão do papel do trabalho doméstico, podem cuidar dos irmãos mais novos enquanto os pais trabalham no mercado. A variável Creche $_{i t}$ é a proxy para a oferta de creche no setor censitário no qual o indivíduo $i$ reside no ano $t$.

A variável $I_{d o s o}$ it é uma dummy igual a um se o domicílio no qual o indivíduo $i$ reside tem um idoso (acima de 75 anos) residente. A presença de pessoas acima de 75 anos pode gerar um efeito negativo na jornada de trabalho no mercado e efeito positivo na jornada de trabalho doméstico, pois a família (em particular, a mulher) pode representar uma fonte importante de assistência a estas pessoas (CAMARANO, 2014). Vale, no entanto, observar que, nos últimos anos, tem havido uma elevação da participação da renda do idoso na renda familiar, levando um número crescente de adultos a se tornar, de alguma forma, dependente dos recursos dos pais ou avós idosos (CAMARANO; EL GHAORI, 1999). Tal fator pode gerar um desincentivo na participação e na jornada de trabalho desses adultos no mercado de trabalho.

A variável $R e n d a_{i t}$ indica a renda familiar líquida da renda do indivíduo $i$, isto é, representa a agregação da renda de todos os residentes do domicílio exclusive do indivíduo $i$; e $m_{-}$lavar $_{i t}$ é uma dummy igual a um se o domicílio em que o indivíduo $i$ reside tem máquina de lavar. Por fim, foram incluídas no modelo variáveis geográficas dummies que indicam a unidade federativa (UF) do domicílio e se o domicílio em questão se localiza em área urbana e região metropolitana. 
A Tabela 2 apresenta os coeficientes das principais variáveis demográficas utilizadas nas regressões das jornadas de trabalho no mercado, doméstico e lazer (equação 15). ${ }^{20} \mathrm{~A}$ maior parte dos coeficientes mostra-se estatisticamente significativa. Os sinais dos mesmos corroboram com o esperado e com o que a literatura advoga (BARBOSA, 2018; QUEIROZ; ARAGÓN, 2015). Algumas variáveis apresentam efeitos semelhantes na comparação entre os sexos. Por exemplo, quanto maior a idade, menor é o tempo dedicado ao mercado de trabalho e maior é o tempo dedicado ao lazer. A educação tem um impacto positivo nas horas dedicadas ao mercado de trabalho, sendo o efeito mais acentuado para as mulheres. Com relação ao trabalho doméstico, um nível de escolaridade mais alto tem efeito negativo na jornada das mulheres e positivo na dos homens. Ou seja, mulheres com maior escolaridade trabalham menos em casa e homens com nível de educação mais elevado trabalham mais em casa. 0 tempo dedicado ao lazer é menor quanto maior for o nível educacional de homens e mulheres. Ser chefe de família, independentemente do sexo, aumenta a jornada de trabalho no mercado e em afazeres domésticos, o que reduz o lazer.

A variável associada à presença de filhos entre 0 e 4 anos é um fator inibidor para a jornada da mulher na força de trabalho; porém, a presença de filhas adolescentes acima de 15 anos de idade pode gerar incentivos para a jornada da mulher no mercado de trabalho, na medida em que haveria uma realocação entre mãe e filha das obrigações domésticas, como o cuidado da casa e dos filhos menores. Essa relação pode ser verificada pelo efeito da variável associada à filha com mais de 15 anos na jornada de trabalho em afazeres domésticos da mulher. Interessante observar que a presença de filhos (do sexo masculino) com mais de 15 anos de idade tem efeito positivo na jornada de trabalho doméstico das mulheres. Tais resultados corroboram grande parte dos estudos que focam na análise de arranjos informais da substituição do trabalho doméstico da mulher pelo de outras muIheres no domicílio (BARBOSA, 2014; COSTA, 2007). Os efeitos da presença de filhos nas jornadas de trabalho (remunerado e não remunerado) dos homens divergem um pouco daqueles encontrados para as mulheres. Como observado anteriormente, filhos pequenos (com menos de quatro anos) aumentam a jornada de trabalho no mercado. Essas diferenças reforçam o forte viés de gênero existente na divisão de trabalho (no mercado e em casa), uma vez que as atividades em afazeres domésticos permanecem, em grande parte, tarefas realizadas apenas pelas mulheres (SORJ; FONTES; MACHADO, 2007).

Como esperado, o efeito avaliado pela variável Creche é positivo para a jornada de trabalho das mulheres tanto no mercado quanto nos afazeres domésticos e negativo para o tempo dedicado ao lazer. Para os homens, o coeficiente do "efeito creche" foi não significativo em relação à jornada de trabalho no mercado e positivo para afazeres domésticos.

\footnotetext{
${ }^{20}$ Como o modelo inclui mais de 50 variáveis, não foi possível apresentar todos os resultados. A Tabela 2 traz apenas os resultados das principais variáveis demográficas que podem gerar efeitos na alocação do tempo entre homens e mulheres. Para simplificação e maior clareza na apresentação dos resultados, as variáveis geográficas, entre outras dummies associadas à idade, educação e faixa etária de filhos, foram excluídas da tabela.
} 
TABELA 2

Coeficientes das principais variáveis demográficas, segundo sexo Brasil - 2001-2015

\begin{tabular}{|c|c|c|c|c|c|c|}
\hline & Idade & Raça & Educa & Casado & Chefe & Filho $_{0 \mathrm{a} 4}$ \\
\hline \multicolumn{7}{|l|}{ Mulheres } \\
\hline \multirow[t]{2}{*}{ Trabalho no mercado } & $-15,42$ & $-0,24$ & 10,92 & $-2,30$ & 4,15 & $-5,51$ \\
\hline & $(0,092)^{\star \star \star}$ & $(0,042)^{\star \star \star}$ & $(0,060)^{\star \star \star}$ & $(0,050)^{\star \star \star}$ & $(0,050)^{\star \star \star}$ & $(0,057)^{\star \star \star}$ \\
\hline \multirow[t]{2}{*}{ Trabalho doméstico (afazeres) } & 8,14 & $-0,51$ & $-3,98$ & 7,88 & 0,40 & 5,50 \\
\hline & $(0,069)^{\star \star \star}$ & $(0,032)^{\star \star \star}$ & $(0,045)^{\star \star \star}$ & $(0,038)^{\star \star \star}$ & $(0,038)^{\star \star \star}$ & $(0,043)^{\star \star \star}$ \\
\hline \multirow[t]{2}{*}{ Lazer } & 7,27 & 0,76 & $-6,94$ & $-5,58$ & $-4,56$ & 0,01 \\
\hline & $(0,092)^{\star \star \star}$ & $(0,042)^{\star \star \star}$ & $(0,060)^{\star \star \star}$ & $(0,050)^{\star \star \star}$ & $(0,050)^{\star \star \star}$ & $(0,057)$ \\
\hline \multicolumn{7}{|l|}{ Homens } \\
\hline \multirow[t]{2}{*}{ Trabalho no mercado } & $-15,59$ & 0,40 & 3,70 & 5,55 & 3,32 & 0,95 \\
\hline & $(0,089)^{\star \star \star}$ & $(0,041)^{\star \star \star}$ & $(0,057)^{\star \star \star}$ & $(0,054)^{\star \star \star}$ & $(0,049)^{\star \star \star}$ & $(0,054)^{\star \star \star}$ \\
\hline \multirow[t]{2}{*}{ Trabalho doméstico (afazeres) } & 2,19 & $-0,54$ & 0,46 & $-2,84$ & 3,12 & 0,68 \\
\hline & $(0,035)^{\star \star \star}$ & $(0,016)^{\star \star \star}$ & $(0,023)^{\star \star \star}$ & $(0,021)^{\star \star \star}$ & $(0,020)^{\star \star \star}$ & $(0,021)^{\star \star \star}$ \\
\hline \multirow[t]{3}{*}{ Lazer } & 13,40 & 0,14 & $-4,16$ & $-2,71$ & $-6,44$ & $-1,63$ \\
\hline & $(0,091)^{\star \star \star}$ & $(0,042)^{\star \star \star}$ & $(0,058)^{\star \star \star}$ & $(0,055)^{\star \star \star}$ & $(0,050)^{\star \star \star}$ & $(0,055)^{\star \star \star}$ \\
\hline & Filho $_{15 \mathrm{a} 19}$ & Filha $_{15 \mathrm{a} 19}$ & Creche & Idoso & Renda & $\begin{array}{l}\text { Maq. } \\
\text { Lavar }\end{array}$ \\
\hline \multicolumn{7}{|l|}{ Mulheres } \\
\hline \multirow[t]{2}{*}{ Trabalho no mercado } & 0,17 & 1,19 & 0,44 & $-2,76$ & 0,00 & 1,89 \\
\hline & $(0,059)^{\star \star \star}$ & $(0,062)^{\star \star \star}$ & $(0,038)^{\star \star \star}$ & $(0,095)^{\star \star \star}$ & $(0,000)^{\star \star \star}$ & $(0,046)^{\star \star \star}$ \\
\hline \multirow[t]{2}{*}{ Trabalho doméstico (afazeres) } & 1,50 & $-0,38$ & 0,25 & 1,08 & 0,00 & $-1,31$ \\
\hline & $(0,045)^{\star \star \star}$ & $(0,047)^{\star \star \star}$ & $(0,029)^{\star \star \star}$ & $(0,071)^{\star \star \star}$ & $(0,000)^{\star \star \star}$ & $(0,035)^{\star \star \star}$ \\
\hline \multirow[t]{2}{*}{ Lazer } & $-1,67$ & $-0,81$ & $-0,69$ & 1,68 & 0,00 & $-0,58$ \\
\hline & $(0,059)^{\star \star \star}$ & $(0,062)^{\star \star \star}$ & $(0,038)^{\star \star \star}$ & $(0,095)^{\star \star \star}$ & $(0,000)^{\star \star \star}$ & $(0,046)$ \\
\hline \multicolumn{7}{|l|}{ Homens } \\
\hline \multirow[t]{2}{*}{ Trabalho no mercado } & 1,06 & 1,24 & 0,32 & $-2,81$ & 0,00 & 0,49 \\
\hline & $(0,061)^{\star \star \star}$ & $(0,066)^{\star \star \star}$ & $(0,037)$ & $(0,094)^{\star \star \star}$ & $(0,094)^{\star \star \star}$ & $(0,045)^{\star \star \star}$ \\
\hline \multirow[t]{2}{*}{ Trabalho doméstico (afazeres) } & $-0,47$ & $-1,13$ & 0,14 & $-0,26$ & 0,00 & $-0,52$ \\
\hline & $(0,024)^{\star \star \star}$ & $(0,026)^{\star \star \star}$ & $(0,015)^{\star \star \star}$ & $(0,037)^{\star \star \star}$ & $(0,000)^{\star \star \star}$ & $(0,018)^{\star \star \star}$ \\
\hline \multirow[t]{2}{*}{ Lazer } & $-0,59$ & $-0,11$ & $-0,17$ & 3,06 & 0,00 & 0,02 \\
\hline & $(0,063)^{\star \star \star}$ & $(0,067)$ & $(0,038)^{\star \star \star}$ & $(0,096)^{\star \star \star}$ & $(0,000)^{\star \star \star}$ & $(0,046)$ \\
\hline
\end{tabular}

Fonte: IBGE. Pesquisa Nacional por Amostra de Domicílios - PNAD. Elaboração da autora.

Nota: A variável Idade corresponde à variável dummy da faixa 60-64 anos de idade. A variável Educa corresponde à variável dummy de nível educacional com mais de 11 anos de idade. A variável Renda corresponde à renda familiar líquida da renda da própria pessoa.

*** Nível de significância de $1 \%$.

Os coeficientes das dummies de ano descrevem como o tempo médio gasto em uma determinada atividade (trabalho no mercado, trabalho doméstico, deslocamento trabalho-casa-trabalho e lazer) tem mudado ao longo do tempo, com controle das mudanças em variáveis demográficas importantes anteriormente especificadas. 0 ano de 2001 é omitido e os coeficientes devem ser interpretados, portanto, como desvios das horas semanais de 2001.

Os Gráficos 4 e 5 apresentam as tendências em relação ao uso do tempo para as atividades de trabalho, deslocamento e lazer com base nos coeficientes de cada ano, sendo 
2001 tomado como ano-base. ${ }^{21}$ De forma geral, estes gráficos replicam os resultados mostrados anteriormente quanto à evolução do uso do tempo por sexo no Brasil, ao longo dos primeiros 15 anos do século XXI.

O Gráfico 4 mostra que, para os homens, comparando-se os anos de 2001 e 2015, o tempo dedicado ao trabalho no mercado sofreu uma queda de quatro horas semanais. Para as mulheres, houve uma estabilidade das horas trabalhadas no mercado em boa parte do período. No entanto, se 2015 for comparado com 2001, a jornada de trabalho no mercado das mulheres apresentou uma queda de duas horas semanais. ${ }^{22}$ Com relação ao tempo dedicado aos afazeres domésticos, os homens apresentaram um leve aumento (um pouco mais de uma hora semanal entre 2001 e 2015) e as mulheres reduziram de forma expressiva o tempo dedicado a esta atividade (redução de sete horas semanais no período analisado).

GRÁFICO 4

Tendências do tempo gasto no trabalho no mercado e nos afazeres domésticos, por sexo Brasil - 2001-2015

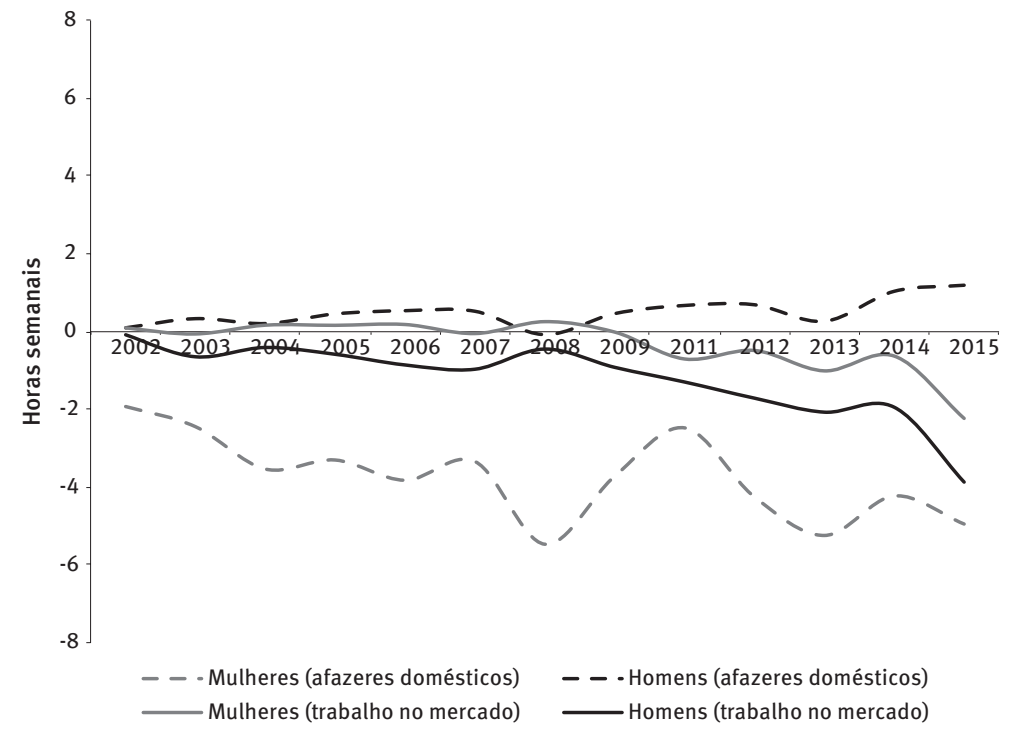

Fonte: IBGE. Pesquisa Nacional por Amostra de Domicílios - PNAD. Elaboração da autora.

O Gráfico 5 mostra a tendência em relação ao uso do tempo dedicado ao lazer. Tanto homens quanto mulheres experimentaram uma elevação de lazer entre 2001 e 2015. Nesse período o aumento foi maior para as mulheres (sete horas semanais) do que para os homens (três horas). Como visto anteriormente, a elevação de lazer para as mulheres se deu pela redução bastante significativa de suas horas dedicadas aos afazeres domésticos, enquanto para os homens foi fruto da diminuição das horas de trabalho no mercado, que



${ }^{22}$ Vale lembrar que, quando analisada sem controles, a evolução da jornada de trabalho no mercado apresenta uma elevação de duas horas semanais no período de 2001 a 2014, e uma queda de duas horas de 2014 para 2015.
} 
foi em maior proporção do que o leve aumento das horas dedicadas aos afazeres domésticos. Por fim, vale observar que esses movimentos explicam, em parte, as tendências mostradas na redução do diferencial de horas de lazer entre homens e mulheres, que ainda é superior para eles.

GRÁFICO 5

Tendências do tempo gasto no lazer, por sexo

Brasil - 2001-2015



- Mulheres _Homens

Fonte: IBGE. Pesquisa Nacional por Amostra de Domicílios - PNAD. Elaboração da autora.

\section{Considerações finais}

O objetivo deste texto foi documentar tendências na alocação do tempo no Brasil no período 2001-2015. A metodologia adotada se baseou no estudo de Aguiar e Hurst (2007), que documentaram as tendências na alocação do tempo ao longo de um período de $\mathbf{4 0}$ anos para os Estados Unidos.

Os resultados encontrados sugerem que, no Brasil, homens desfrutam de mais horas de lazer do que as mulheres, ainda que haja uma tendência de redução dessa diferença ao longo do tempo. Há uma elevação do tempo dedicado ao lazer para ambos os sexos, o que ocorre de forma mais acentuada para as mulheres. Os resultados mostram ainda que o aumento no número de horas de lazer ao longo do período foi ocasionado por razões diversas: para os homens o acréscimo de quatro horas semanais entre 2001 e 2015 deveu-se à redução expressiva nas horas trabalhadas no mercado e ao leve aumento nas horas dedicadas aos afazeres domésticos; e, para as mulheres brasileiras, a elevação de sete horas semanais no mesmo período pode ser explicada pelo decréscimo nas horas dedicadas aos afazeres domésticos e pela estabilidade nas horas direcionadas ao trabalho no mercado. Em termos demográficos, o estudo mostra que o aumento do lazer prevaleceu entre as pessoas (homens e mulheres) com menor qualificação (ensino superior incompleto), solteiras e sem filhos. 
A definição de lazer adotada foi feita de forma residual, isto é, o lazer foi definido como o tempo não despendido nas atividades de trabalho (remunerado e não remunerado) e no deslocamento casa-trabalho-casa. Ainda que, e como já exposto ao longo do texto, Aguiar e Hurst (2007) encontraram tendências semelhantes na evolução do uso do tempo entre essa definição residual de lazer e outras medidas de lazer (associadas diretamente com atividades sociais e de entretenimento), uma limitação deste estudo é não ter disponibilidade de uma pesquisa de uso do tempo. 0 refinamento desta definição residual de lazer só se torna possível com pesquisas específicas sobre uso do tempo para o Brasil, que podem contribuir de forma significativa para análise mais precisa de atividades de uso do tempo direcionadas além do mercado.

Existem diversas extensões possíveis para este estudo. A primeira delas é analisar de forma mais detalhada se fatores demográficos, de fato, contribuíram ou não para as tendências das atividades de uso do tempo apresentadas. Os resultados desse estudo sugerem que as mudanças na alocação do uso do tempo e nas desigualdades de gênero mostradas podem ter sido muito mais fruto de transformações no comportamento das pessoas e nas normas sociais do que de mudanças demográficas. Prescrições sociais como o "homem deve ser o provedor e trabalhar no mercado e a mulher deve ser dona de casa e cuidar dos filhos" podem ainda ter destaque na explicação de porque os homens brasileiros mudaram tão pouco sua jornada de afazeres domésticos ao longo do tempo, por exemplo. A literatura sobre o impacto das normas sociais no viés de gênero e divisão do trabalho ainda é bastante incipiente no Brasil. Em um dos poucos estudos existentes, por exemplo, Codazzi, Pero e Sant'Anna (2018) sugerem que quanto maiores as chances de a mulher ganhar mais do que o marido, menor é a propensão de a mulher participar da força de trabalho e, uma vez no mercado de trabalho, maior é a probabilidade de o salário efetivo ser menor do que o potencial, de a jornada de trabalho ser menor e de o emprego ser informal. Pinheiro (2018), por sua vez, sugere que a maioria das desigualdades de gênero no trabalho reprodutivo deve-se a fatores não observáveis associados ao "termo de gênero". A autora mostra ainda que o peso das normas e convenções de gênero é extremamente importante mesmo entre as mulheres que possuem maior renda do que seus parceiros e que, portanto, poderiam barganhar para se retirar do trabalho doméstico. As jornadas de trabalho doméstico dessas mulheres tendem a ser ainda maiores do que quando elas possuíam menor renda do que seus cônjuges. Tais resultados só reforçam o fato de que as normas sociais, no Brasil, têm um papel bastante relevante nas questões de gênero e divisão de trabalho, seja ele remunerado ou não.

Outra extensão trata de uma análise mais aprofundada entre renda e alocação do tempo no Brasil. Em estudo recente, Olmos (2017) sugere que, em países desenvolvidos, há um diferencial do tempo de lazer com relação à renda, com os indivíduos mais pobres desfrutando de mais lazer do que os mais ricos. Nos países em desenvolvimento, o autor sugere a relação oposta: indivíduos mais pobres em renda são também mais pobres em tempo de lazer. A diferença nos perfis de lazer entre esses países ocorre majoritariamente devido às desigualdades no acesso da população a serviços básicos e à prevalência de trabalho de 
subsistência nos países em desenvolvimento. Nesse contexto, uma investigação da evolução da desigualdade do uso do tempo também é um tema que merece atenção. Por fim, um tópico interessante para pesquisas futuras é investigar as desigualdades de gênero existentes dentro da família e avaliar o impacto destas desigualdades na alocação do uso do tempo no trabalho e, consequentemente, no lazer de cada membro da família.

\section{Referências}

AGUIAR, M.; HURST, E. Consumption vs. expenditure. Journal of Political Economy, v. 113, n. 5 , p. 919-948, 2005a.

. Lifecycle prices and production. Cambridge: NBER, 2005b. (Working Paper, n. 11.601). Measuring leisure: the allocation of time over five decades. Quarterly Journal of Economics, v. 122, n. 3, p. 969-1006, Aug. 2007.

The increase of leisure inequality: 1965-2005. Washington: Aei Press, 2009.

AGUIAR, M.; HURST, E.; KARABARBOUNIS, L. Recent developments in economics of time use. The Annual Review of Economics, v. 4, p. 373-397, 2012.

BARAJAS, M. L. Avanços na América Latina na medição e valoração do trabalho não remunerado realizado pelas mulheres. In: FONTOURA, N.; ARAÚJO, C. (Org.). Uso do tempo e gênero. Rio de Janeiro: UERJ, 2016.

BARBOSA, A. L. N. H. Tendências nas horas dedicadas ao trabalho e lazer: uma análise da alocação do tempo no Brasil. Rio de Janeiro: Ipea, 2018 (Texto para Discussão, n. 2416).

Participação feminina na força de trabalho brasileira: evolução e determinantes. In: CAMARANO, A. A. Novo regime demográfico: uma nova relação entre população e desenvolvimento? Rio de Janeiro: Ipea, 2014. p. 407-442.

BARBOSA, A. L. N. H.; COSTA, J. Oferta de creche e participação das mulheres no mercado de trabalho no Brasil. Mercado de Trabalho - Conjuntura e Análise, ano 23, n. 62, p 23-35, 2017.

BARROS, R. P.; OLINTO, P.; LUNDE, T.; DE CARVALHO, M. The impact of access to free childcare on women's labor market outcomes: evidence from a randomized trial in low-income neighborhoods of Rio de Janeiro. Washington: World Bank, 2011.

BECKER, G. S. A theory of the allocation of time. Economic Journal, v. 75, n. 29, p. 493-517, 1965.

The economic approach to human behavior. Chicago: The University of Chicago Press, 1976.

BENHABIB, J.; ROGERSON, R.; WRIGHT, R. Homework in macroeconomics: household production and aggregate fluctuations. The Journal of Political Economy, v. 99, n. 6, p. 1166-1187, Dec. 1991.

BIDDLE, J.; HAMERMESH, D. Sleep and the allocation of time. Journal of Political Economy, v. 98, n. 5 , p. $922-941,1990$.

BIRCH, E. R.; LE, A. T.; MILLER, P. W. Time use surveys. In: BIRCH, E. R.; LE, A. T.; MILLER, P. W. (Ed.). Household divisions of labour. London: Palgrave Macmillan, 2009. cap. 2.

BUSSAB, W.; MORETTIN, P. Estatística básica. 4. ed. São Paulo: Atual, 1987.

BROWNING, M.; CHIAPPORI, P. A.; WEISS, Y. Economics of the family. Cambridge: United Kingdom: University Press, 2014. 
CAMARANO, A. A. (Org.). Novo regime demográfico: uma nova relação entre população e desenvolvimento? Rio de Janeiro: Ipea, 2014.

CAMARANO, A. A.; EL GHAOURI, S. K. Idosos brasileiros: que dependência é essa? In: CAMARANO, A. A. (Org.). Muito além dos 60: os novos idosos brasileiros. Rio de Janeiro: Ipea, 1999. p. 281-306.

CAMPOS, A. Trabalho e tempo livre. Brasília: Ipea, 2012. (Texto para Discussão, n. 1767).

CAMPOS, A.; PHINTENER, M. Tempos sociais no Brasil: a experiência de distintos grupos etários nos anos recentes. In: MACAMBIRA, J.; ARAÚJO, T.; LIMA, R. (Org.). Mercado de trabalho: qualificação, emprego e políticas sociais. Fortaleza: IDT, 2016a.

. Tempos sociais de jovens no Brasil urbano. In: SILVA, E.; BOTELHO, R. (Org.). Dimensões da experiência juvenil brasileira e novos desafios às políticas públicas. Brasília: Ipea, 2016b.

CODAZZI, K.; PERO, V.; SANT'ANNA, A. A. Social norms and female labor participation in Brazil. Review of Development Economics, v. 22, n. 4, p. 1513-1535, 2018.

COSTA, D. From mill town to board room: the rise of women's paid labor. Journal of Economic Perspectives, v. 14, n. 4, p. 101-122, 2000.

COSTA, J. S. M. Determinantes da participação feminina no mercado de trabalho brasileiro. 2007. Tese (Mestrado) - Universidade de Brasília, Brasília, 2007.

FONTOURA, N. et al. Pesquisas de uso do tempo no Brasil: contribuições para a formulação de políticas de conciliação entre trabalho, família e vida pessoal. Revista Econômica, Rio de Janeiro, v. 12, n. 1, p. 11-46, jun. 2010.

GOLDIN, C. Life-cycle labour force participation of married women: historical evidence and implications. Journal of Labour Economics, v. 7, n. 1, p. 20-47, 1989.

GREENWOOD, J.; GUNER, N.; KOCHARKOV, G.; SANTOS, C. Technology and the changing family: a unified model of marriage, divorce, educational attainment, and married female labor-force participation. American Economic Journal: Macroeconomics, v. 8, n. 1, p. 1-41, Jan. 2016.

GREENWOOD, J.; VANDENBROUCKE, G. Hours worked: long-run trends. In: DURLAUF, S. N.; BLUME, L. E. The new palgrave dictionary of economics. 2. ed. United Kingdom: Palgrave Macmillan, 2008.

GREENWOOD, J.; SESHADRI, A.; YORUKOGLU, M. Engines of liberation. Review of Economic Studies, v. 72, n. 1, p. 109-133, 2005.

GRONAU, R. Home production: a survey. In: ASHENFELTER, O.; LAYARD, R. (Ed.). Handbook of labor economics. Amsterdam: North Holand, 1986. p. 273-303.

HECKMAN, J. Effects of child-care programs on women's work effort. Journal of Political Economy, v. 82 , n. 2, p. 136-163, 1974.

Introduction to a theory of the allocation of time by Gary Becker. Germany: IZA, 2014. (Discussion Paper, n. 8424).

INADA, K. On a two-sector model of economic growth: comments and a generalizations. Review of Economic Studies, v. 30, n. 2, p. 119-127, 1963.

KOPECKY, K. The trend in retirement. International Economic Review, v. 52, n. 2, p. 287-316, 2011.

KRUEGER, D.; PERRI, F. Does income inequality lead to consumption inequality? Evidence and theory. Review of Economic Studies, v. 73, n. 1, p. 163-193, Jan. 2006.

KURODA, S. Do japanese work shorter hours than before? Measuring trends in market work and leisure using 1976-2006 japanese time use surveys. Journal of the Japanese and International Economies, v. 24, n. 4, p. 481-502, 2010. 
Leisure. Japan Labor Review, v. 10, n. 4, p. 16-23, 2013.

MELO, H. P.; CONSIDERA, C. M.; DI SABBATO, A. Os afazeres domésticos contam. Economia e Sociedade, Campinas, v. 16, n. 3, p. 435-454, dez. 2007.

MINCER, J. Labor force participation of married women: a study of labor supply. In: UNIVERSITIESNATIONAL BUREAU COMMITTEE FOR ECONOMICA RESEARCH. Aspects of labor economics. Princeton: National Bureau of Economic Research, 1962.

Market prices, opportunity costs, and income effects. In: CHRIST, C. (Ed.). Measurement in economics. Stanford: Stanford University Press, 1963.

1993. v. 2.

Studies in labor supply: collected essays of Jacob. United Kingdom: Edward Elgar,

OLMOS, P. Time poverty in developing countries. Mimeografado.

ONU - Organização das Nações Unidas. Declaração e plataforma de ação da IV Conferência Mundial sobre a Mulher. Pequim: ONU, 1995.

POSADAS, J. Grandparents as child care providers: factors to consider designing child care policies. Washington: World Bank, 2012. (Economic Promise, n. 101).

PEREIRA, R. H.; SCHWANEN, T. Tempo de deslocamento casa-trabalho no Brasil (1992-2009): diferenças entre regiões metropolitanas, níveis de renda e sexo. Brasília: Ipea, 2013. (Texto para Discussão, n. 1813).

PINHEIRO, L. S. 0 trabalho nosso de cada dia: determinantes do trabalho doméstico de homens e mulheres no Brasil. Tese (Doutorado) - Universidade de Brasília, Instituto de Ciências Sociais, Departamento de Sociologia, Brasília, 2018.

POLLAK, R.; WACHTER, M. The relevance of the household production function and its implications for the allocation of time. Journal of Political Economy, v. 83, n. 2, p. 255-277, 1975.

QUEIROZ, V. S.; ARAGÓN, J. A. O. Alocação de tempo em trabalho pelas mulheres brasileiras. Estudos Econômicos, São Paulo, v. 45, n. 4, p. 787-819, out.-dez. 2015.

ROBINSON, J.; GODBEY, G. Time for life: the surprising ways americans use their time. 2. ed. Pennsylvania: Penn State University Press, 1999.

SOARES, C.; SABOIA, A. L. Tempo, trabalho e afazeres domésticos: um estudo com base nos dados da Pesquisa Nacional por Amostra de Domicílios de 2001 e 2005. Rio de Janeiro: IBGE, 2007. (Texto para Discussão, n. 21).

SORJ, B.; FONTES, A.; MACHADO, D. Políticas e práticas de conciliação entre família e trabalho no Brasil. Cadernos de Pesquisa, v. 37, n. 132, p. 573-594, set./dez. 2007.

SIMINSKI, P. The effect of earnings on housework: pros and cons of HILDA's time use data items. In: ACSPRI SOCIAL SCIENCE METHODOLOGY CONFERENCE, 6., 2006, Sydney. Proceedings... Sydney: ACSPRI, Dec. 2006.

STEWART, J. Tobit or not Tobit? Germany: IZA, 2009. (Discussion Paper Series, n. 4588).

UNITED NATIONS. Guide to producing statistics on time use: measuring paid and unpaid work. New York: United Nations, 2005.

The worlds women 2015: trends and statistics. New York: United Nations, 2015.

VANDENBROUCKE, G. A model of the trends in hours. New York: University of Rochester, 2005. (Research Report, n. 11). 


\title{
Sobre a autora
}

Ana Luiza Neves de Holanda Barbosa é técnica de planejamento e pesquisa da Diretoria de Estudos e Políticas Sociais (Disoc) do Instituto de Pesquisa Econômica Aplicada (Ipea), Rio de Janeiro. Professora do Instituo Brasileiro de Mercado de Capitais do Rio de Janeiro (IBMEC RJ).

\section{Endereço para correspondência}

Avenida Rui Barbosa 100, 1301, Flamengo

22250-020 - Rio de Janeiro-RJ, Brasil

\begin{abstract}
Trends in allocation of time in Brazil: labor and leisure

In this study, we document trends in the allocation of time by gender in Brazil. In particular, we analyze trends in market working hours, home working hours (household chores), and leisure times in Brazil between 2001 and 2015. The analysis was done by gender, and is based on the National Household Survey (PNAD). Results show men enjoy more leisure time than women, although this difference is decreasing over time. For both men and women, there is an increase in leisure time. Specifically, we show that leisure for men increased by 4 hours per week (driven by a decline in market working hours) whereas the increase amounted to 7 hours per week for women (driven by a decline in domestic production working hours).
\end{abstract}

Keywords: Time use. Leisure. Labor supply. Gender.

\section{Resumen}

Asignación del tiempo en Brasil: trabajo y ocio

El objetivo de este estudio es documentar las tendencias en la distribución del tiempo por género en Brasil entre 2001 y 2015. En particular, se analizan la evolución de las jornadas semanales de trabajo en el mercado y en las tareas domésticas, además del tiempo semanal dedicado al ocio. El análisis se hace por sexo y toma como base la encuesta nacional de hogares (PNAD por sus siglas en portugués). Los resultados muestran que los hombres brasileros disfrutan de más horas de ocio que las mujeres, aunque haya una tendencia a la reducción de esta diferencia a lo largo del tiempo. Hay un aumento del tiempo dedicado al ocio tanto en hombres como en mujeres, aunque de forma más acentuada en estas últimas. En concreto, los resultados muestran además que el aumento del número de horas a lo largo del período de estudio fue ocasionado por razones diferentes entre hombres y mujeres. Para los hombres, el aumento del tiempo de ocio (de cuatr horas semanales) puede explicarse por la reducción significativa de las horas tabajadas en el mercado, mientras que, para las mujeres este aumento (siete horas semanales) se explicaría por la reducción del tiempo dedicado a las tareas domésticas.

Palabras clave: Uso del tiempo. Ocio. Oferta laboral. Sexo-género. 


\section{Anexo}

Coeficientes das dummies de ano, por sexo

\begin{tabular}{|c|c|c|c|c|c|c|c|}
\hline Variáveis & 2002 & 2003 & 2004 & 2005 & 2006 & 2007 & 2008 \\
\hline \multicolumn{8}{|l|}{ Mulheres } \\
\hline \multirow[t]{2}{*}{ Trabalho no mercado } & 0,09 & $-0,06$ & 0,17 & 0,16 & 0,19 & $-0,05$ & 0,26 \\
\hline & $(0,102)$ & $(0,102)$ & $(0,101)^{\star \star}$ & $(0,100)^{\star \star}$ & $(0,063)^{\star \star}$ & $(0,100)$ & $(0,100)^{\star \star \star}$ \\
\hline \multirow[t]{2}{*}{ Trabalho doméstico (afazeres) } & $-1,91$ & $-2,44$ & $-3,53$ & $-3,30$ & $-3,82$ & $-3,34$ & $-5,46$ \\
\hline & $(0,077)^{\star \star \star}$ & $(0,077)^{\star \star \star}$ & $(0,076)^{\star \star \star}$ & $(0,075)^{\star \star \star}$ & $(0,075)^{\star \star \star}$ & $(0,075)^{\star \star \star}$ & $(0,076)^{\star \star \star}$ \\
\hline \multirow[t]{2}{*}{ Lazer } & 1,83 & 2,50 & 3,36 & 3,13 & 3,63 & 3,38 & 5,20 \\
\hline & $(0,102)^{\star \star \star}$ & $(0,102)^{\star \star \star}$ & $(0,101)^{\star \star \star}$ & $(0,101)^{\star \star \star}$ & $(0,100)^{\star \star \star}$ & $(0,100)^{\star \star \star}$ & $(0,100)^{\star \star \star}$ \\
\hline \multicolumn{8}{|l|}{ Homens } \\
\hline \multirow[t]{2}{*}{ Trabalho no mercado } & $-0,10$ & $-0,64$ & $-0,40$ & $-0,58$ & $-0,85$ & $-0,96$ & $-0,45$ \\
\hline & $(0,098)$ & $(0,098)^{\star \star \star}$ & $(0,097)^{\star \star \star}$ & $(0,096)^{\star \star \star}$ & $(0,096)^{\star \star \star}$ & $(0,096)^{\star \star \star}$ & $(0,097)^{\star \star \star}$ \\
\hline \multirow[t]{2}{*}{ Trabalho doméstico (afazeres) } & 0,10 & 0,34 & 0,21 & 0,46 & 0,54 & 0,53 & $-0,07$ \\
\hline & $(0,039)^{\star \star}$ & $(0,039)^{\star \star \star}$ & $(0,038)^{\star \star \star}$ & $(0,038)^{\star \star \star}$ & $(0,038)^{\star \star \star}$ & $(0,038)^{\star \star \star}$ & $(0,038)^{\star \star \star}$ \\
\hline \multirow[t]{2}{*}{ Lazer } & 0,00 & 0,31 & 0,19 & 0,12 & 0,31 & 0,44 & 0,52 \\
\hline & $(0,100)$ & $(0,100)^{\star \star \star}$ & $(0,100)^{\star \star}$ & $(0,098)$ & $(0,098)^{\star \star \star}$ & $(0,098)^{\star \star \star}$ & $(0,099)^{\star \star \star}$ \\
\hline Variáveis & 2009 & 2011 & 2012 & 2013 & 2014 & 2015 & \\
\hline \multicolumn{8}{|l|}{ Mulheres } \\
\hline \multirow[t]{2}{*}{ Trabalho no mercado } & $-0,01$ & $-0,70$ & $-0,48$ & $-1,01$ & $-0,63$ & $-2,23$ & \\
\hline & $(0,098)$ & $(0,102)^{\star \star \star}$ & $(0,102)^{\star \star \star}$ & $(0,102)^{\star \star \star}$ & $(0,102)^{\star \star \star}$ & $(0,103)^{\star \star \star}$ & \\
\hline \multirow[t]{2}{*}{ Trabalho doméstico (afazeres) } & $-3,71$ & $-2,47$ & $-4,25$ & $-5,24$ & $-4,22$ & $-4,94$ & \\
\hline & $(0,075)^{\star \star \star}$ & $(0,077)^{\star \star \star}$ & $(0,077)^{\star \star \star}$ & $(0,077)^{\star \star \star}$ & $(0,077)^{\star \star \star}$ & $(0,077)^{\star \star \star}$ & \\
\hline \multirow[t]{2}{*}{ Lazer } & 3,72 & 3,17 & 4,73 & 6,24 & 4,85 & 7,17 & \\
\hline & $(0,100)^{\star \star \star}$ & $(0,102)^{\star \star \star}$ & $(0,102)^{\star \star \star}$ & $(0,102)^{\star \star \star}$ & $(0,102)^{\star \star \star}$ & $(0,103)^{\star \star \star}$ & \\
\hline \multicolumn{8}{|l|}{ Homens } \\
\hline \multirow[t]{2}{*}{ Trabalho no mercado } & $-0,92$ & $-1,29$ & $-1,71$ & $-2,07$ & $-1,94$ & $-3,87$ & \\
\hline & $(0,096)^{\star \star \star}$ & $(0,099)^{\star \star \star}$ & $(0,098)^{\star \star \star}$ & $(0,098)^{\star \star \star}$ & $(0,098)^{\star \star \star}$ & $(0,099)^{\star \star \star}$ & \\
\hline \multirow[t]{2}{*}{ Trabalho doméstico (afazeres) } & 0,47 & 0,68 & 0,69 & 0,27 & 1,04 & 1,20 & \\
\hline & $(0,038)^{\star \star \star}$ & $(0,039)^{\star \star \star}$ & $(0,039)^{\star \star \star}$ & $(0,039)^{\star \star \star}$ & $(0,039)^{\star \star \star}$ & $(0,039)^{\star \star \star}$ & \\
\hline \multirow[t]{2}{*}{ Lazer } & 0,45 & 0,62 & 1,01 & 1,80 & 0,90 & 2,67 & \\
\hline & $(0,098)^{\star \star \star}$ & $(0,100)^{\star \star \star}$ & $(0,100)^{\star \star \star}$ & $(0,101)^{\star \star \star}$ & $(0,100)^{\star \star \star}$ & $(0,101)^{\star \star \star}$ & \\
\hline
\end{tabular}

Fonte: IBGE. Pesquisa Nacional por Amostra de Domicílios - PNAD. Elaboração da autora.

Nota: 0 erro-padrão consta entre parênteses.

A diferença entre 2015 e 2001 com teste t não é rejeitada ao nível de significância de $95 \%$.

***, **, * correspondem ao nível de significância de $1 \%, 5 \%$ e $10 \%$, respectivamente. 